\title{
EL PROCESO DE INTERNAMIENTO NO VOLUNTARIO POR RAZÓN DE TRASTORNO PSÍQUICO
}

\author{
Sonia Calaza López
}

Profesora Contratada Doctora de Derecho Procesal de la UNED

Resumen: Este trabajo contiene un minucioso estudio del internamiento no voluntario por razón de trastorno psíquico.

Tras el detallado análisis del proceso especial, ofrecido por el presente estudio, el lector se percatará no sólo de la indispensable creación de un nuevo procedimiento ágil, sencillo, flexible, rápido, eficaz y concentrado, que sea, al propio tiempo, respetuoso con las garantías de la persona hipotéticamente afectada por un "trastorno psíquico", sino también por la correlativa necesidad de regulación ex novo de un segundo procedimiento, destinado, cuando proceda, a la «supervisión" o "control» del internamiento, en el que se dilucide, de un lado, la conveniencia de su mantenimiento o, en caso contrario, de su finalización y, de otro, el adecuado cumplimiento, en el centro de internamiento, del más exquisito respeto a los derechos fundamentales del «interno».

Palabras clave: Internamiento involuntario por razón de trastorno psíquico.

Abstract: This research deals with no voluntary committal caused by psychological disorder.

Este trabajo constituye la síntesis de un capítulo del libro titulado «Los procesos sobre la capacidad de las personas», de reciente aparición en la colección de monografías de la editorial IUSTEL. 
After careful analysis of the special process, drawn from the present study, the reader will realise not only the essential need to create a new procedure which should be agile, simple, flexible, fast and concentrated and which should respect the guarantees of the person allegedly affected by a "psychological disorder». But the reader will also realise the correlative need to regulate ex novo a second procedure aimed, if appropriate, to «supervise» or to "monitor» the committal and by means of which to assess, on the one hand, the convenience of maintaining the committal or contrarily to end it and, on the other hand, the appropriate fulfilment of the exquisite respect of the "patient's» fundamental rights by the mental hospital.

Sumario: I. CONCEPTO, NATURALEZA Y FUNDAMENTO.-1. Concepto.-2. Naturaleza.-3. Fundamento.-II. OBJETO DEL PROCESO.-1. Causas del internamiento.-A. La existencia de un trastorno psíquico.-B. La conveniencia del internamiento con fines terapéuticos.-C. La ausencia de consentimiento.-III. SUJETOS DEL PROCESO.-1. Legitimación activa. A. Solicitud de la «autorización judicial para el internamiento".-B. Solicitud de la "ratificación judicial para el internamiento».-2. Legitimación pasiva.-IV. PROCEDIMIENTO.-1. Interposición de la pretensión.-A. Juzgado competente.-B. Emplazamiento.-2. Práctica de la prueba de cargo destinada a formar la convicción judicial sobre la «autorización» o "ratificación» del internamiento.-A. Audiencia a la persona afectada, al Ministerio Fiscal y a cualquier otra persona cuya comparecencia estime, el Juez, conveniente o le sea solicitada por el afectado por la medida.-B. Examen de la persona afectada por la solicitud de "autorización» o "ratificación» del internamiento.-C. Dictamen de un facultativo designado judicialmente.-V. EFECTOS DE LA RESOLUCIÓN JUDICIAL Y RECURSOS.-1. Resolución judicial de la «autorización» o "ratificación» del internamiento y su control.-2. Los recursos.

\section{CONCEPTO, NATURALEZA Y FUNDAMENTO}

\section{CONCEPTO}

El internamiento no voluntario por razón del trastorno psíquico constituye, en el momento presente, un proceso especial, en virtud del cual el Juez autorizará o, en otro caso, denegará, la práctica médica de la privación de la libertad con fines terapéuticos cuando la perso- 
na afectada por un concreto trastorno psíquico no preste su consentimiento o, en su caso, carezca de la más mínima voluntad para prestarlo.

Este internamiento viene caracterizado, con carácter general, por las notas de "excepcionalidad", "subsidiaridad", "proporcionalidad", «necesidad", «instrumentalidad", «transitoriedad», "provisionalidad» 0 «temporalidad» $\mathrm{y}$ «urgencia».

La «excepcionalidad» o "subsidiaridad» del internamiento ha de referirse a la confirmación judicial de la «imprescindible», «inevitable» o "ineludible» adopción de esta medida extrema para el restablecimiento psíquico del "presunto enfermo", de dónde se infiere que, para lograr este objetivo, no bastará la adopción de cualquier otra medida menos gravosa para éste - como, podría serlo, entre otras, el sometimiento a un concreto tratamiento médico-, debiendo, esta persona, someterse, para su curación, de modo necesario, a un internamiento.

Desde amplios sectores de la Judicatura se ha mostrado ${ }^{1}$, en reiteradas ocasiones, la conveniencia de utilizar, en lugar de la práctica generalizada de internamientos psiquiátricos, alternativas útiles, rápidas, eficaces, beneficiosas y menos gravosas para las personas, como podrían serlo, entre otras, los tratamientos involuntarios ambulatorios por razón de trastorno psíquico.

El internamiento constituye, pues una medida «extrema» o "límite» que tan sólo habrá de adoptarse cuando se prevea, razonablemente, la imposibilidad o, en su caso, la gran dificultad del «restablecimiento» de la persona aquejada por el «trastorno psíquico» de permanecer, ésta persona, en libertad.

1 En este sentido, se ha sugerido, en un Seminario sobre Derecho de Familia y Derecho Civil en materia tutelar de discapacitados, celebrado en octubre de 2003 y organizado por el CGPJ y la Fundación Aequitas, la propuesta de un nuevo texto para incorporar al apartado quinto del artículo 763 de LEC, cuyo contenido fuese: «Podrá también el Tribunal autorizar un tratamiento no voluntario por razón de trastorno psíquico o un período de observación para diagnóstico, cuando así lo requiera la salud del enfermo, previa propuesta razonada del especialista, audiencia del interesado, informe del Forense y Ministerio Fiscal. En la resolución que se dicte deberá establecerse el plan de tratamiento, sus mecanismos de control y el dispositivo sanitario responsable del mismo que deberá informar al Juez, al menos cada tres meses, de su evolución y seguimiento, así como sobre la necesidad de continuar, modificar o cesar el seguimiento. El plazo de duración de esta medida será de dieciocho meses», según la información contenida en el reportaje titulado «El tratamiento ambulatorio involuntario, alternativa al internamiento forzoso», publicado en «La gran revista de política social», p. 16. 
Esta "excepcionalidad» del internamiento encuentra su fundamento en la prioridad, que razonablemente ha de otorgarse, a la libertad frente a la capacidad, de suscitarse un conflicto entre ambos valores ${ }^{2}$.

Los avances habidos en materia de Psiquiatría en nuestro pasado más reciente nos permiten aventurar que la imperiosa necesidad del «internamiento», efectuado con vistas a la «rehabilitación» de los enfermos psíquicos es cada vez menor, pudiendo éstos, en la actualidad, recuperarse con el sometimiento a determinados tratamientos puntuales que no hace mucho tiempo tan sólo podían ser sustituidos por la "privación de libertad» civil, en los entonces denominados "manicomios" y el subsiguiente sometimiento a una constante «observación» psiquiátrica.

$\mathrm{La}$ «proporcionalidad» alude al establecimiento, en el juicio favorable a la pretensión de la incapacitación, de una adecuada ponderación entre la intensidad, gravedad o trascendencia del trastorno psíquico, que, en concreto, afecta al sujeto pasivo del proceso de «internamiento involuntario» y la consabida radicalidad o severidad de esta medida de privación de uno de los bienes más valiosos de que disponen las personas, como lo es la libertad, a la que se ha conferido, por parte de autorizados pensadores ${ }^{3}$, incluso mayor valor que a la propia vida.

La imperiosa "necesidad" del internamiento, que ha de ser decretada por el Juez, en estrecha relación con la «excepcionalidad» de su práctica, encuentra su fundamento, no ya en la razonable «conveniencia» $\mathrm{o}$ "idoneidad" del «internamiento", al objeto de conseguir la pronta recuperación del «supuesto enfermo», sino en su indispensable, indefectible e irremediable adopción, tanto, en sentido positivo, para procurar su «mejoría», como para evitar, en sentido negativo, que esta persona se auto-lesione $\mathrm{o}$, en otro caso, ocasione un perjuicio irreparable a terceras personas.

La resolución judicial sobre la «autorización» o «ratificación» del internamiento constituye, asimismo, un "instrumento" al servicio

${ }^{2}$ Vid., LÓPEZ FRÍAS, M. J., quién apunta esta idea al indicar que "ante un conflicto de intereses, mayor capacidad versus libertad para actuar sobre la propia persona, debe prevalecer esta última ", en "El ejercicio de los derechos personalísimos de los enfermos psíquicos", Revista de Derecho Privado, abril, 1999, p. 299.

3 Vid., en este sentido, entre otros, CARNELUTTI, F., quién afirma rotundamente que "la libertad vale más que la vida, como lo sabe quién por ella rehúsa a la vida», en "Cómo se hace un proceso", Ed. Tremis, 2. ${ }^{\text {a }}$ ed., Sta Fe de Bogotá, Colombia, 1994, p. 6. 
de la resolución principal, que es, en realidad, la decisión médica sobre la conveniencia de dicho internamiento, de tal suerte que la determinación judicial se limita a dotar de cobertura jurídica al dictamen Médico.

La autorización judicial del internamiento no podrá, tal y como se ha advertido ${ }^{4}$, ser considerada como una decisión autónoma e independiente de la resolución adoptada por la autoridad sanitaria, sino que sirve a la misma o la complementa, toda vez que la decisión principal sobre esta medida terapéutica corresponde, en exclusiva, al especialista ${ }^{5}$, no debiendo, en consecuencia, la "autorización» o "ratificación» judicial, suponer un obstáculo o demora para la determinación médica o facultativa de aquella medida de internamiento.

La «transitoriedad», «provisionalidad» 0 «temporalidad» se refiere, lógicamente, a la conveniencia de que la «autorización» o, en su caso, la «ratificación» del internamiento involuntario por razón del trastorno psíquico, sean, siempre y en todo caso, limitadas en el tiempo, debiendo someterse, la situación de internamiento, que, en concreto, hubiere sido adoptada o confirmada, por dicha resolución, a control periódico, al objeto del mantenimiento o la enervación, en lo sucesivo, de esta gravosa medida, consistente en la privación de libertad con fines terapéuticos.

La «urgencia» del procedimiento de «internamiento civil involuntario» encuentra su fundamento, finalmente, en la propia «urgencia» de la atención sanitaria ${ }^{6}$, en régimen cerrado, pendiente de

${ }^{4}$ Vid., en este sentido, ALBIÑANA OLMOS, J. L., «Las urgencias en salud mental: las autorizaciones judiciales de internamientos», Revista General del Derecho, $\mathrm{n}^{\circ}$ 588,1993 , p. 8206.

${ }^{5}$ Vid., PECES MORATE, J. E., quién señala que «si los facultativos especialistas estiman que no se precisa internamiento para el tratamiento del enfermo,..., no es admisible que una decisión del Juez imponga el internamiento contraindicado clínicamente», en "Problemática del internamiento judicial de enfermos psiquiátricos», Actualidad Civil $n^{\circ} 35,22$ a 28 de septiembre, 1986, p. 2431.

6 Esta "urgencia» del "internamiento", motivada por la paralela "urgencia" de asistencia sanitaria del enfermo psíquico ha impulsado a GARCÍA GARCÍA, L. M., incluso, a advertir que «el deber del Estado de proteger la vida y la salud prescindiendo del consentimiento del afectado, no debe extenderse más allá de los supuestos de urgencia con riesgo para la vida o que puedan resultar irreversibles para la integridad y, específicamente, además, en el internamiento de enfermos mentales, en casos de crisis agudas, en que la falta de tratamiento adecuado podría acarrear un deterioro importante o incluso poner en peligro la propia vida del paciente ( suicidio por depresión )", en "Marco jurídico de la enfermedad mental. Incapacitación e internamiento», Ed. Revista General del Derecho, Valencia, 2000, pp. 176 y 177. 
«autorización» o «confirmación judicial», reclamadas por el enfermo, como consecuencia de su «trastorno psíquico».

Ahora bien, la «urgencia», predicable por igual de todas las resoluciones sobre el internamiento de las personas, puede ser, en ciertos casos, sin embargo, de tal intensidad, que haga conveniente la práctica de dicho internamiento, sin autorización previa, quedando, en consecuencia, la adopción de esta medida a expensas de una ulterior ratificación judicial.

Conviene, pues, distinguirse, desde este momento inicial del estudio del proceso de internamiento involuntario por razón de trastorno psíquico, las pretensiones de "autorización», previas a dicho internamiento, de las pretensiones de «ratificación», posteriores a su práctica, siendo estas últimas, según fuentes de la propia Judicatura ${ }^{7}$, las más frecuentes en la práctica de nuestros Juzgados y Tribunales, precisamente por razón de la especial «urgencia» predicable de este tipo de situaciones.

Si la justicia tardía ha venido siendo identificada, con carácter general, por nuestros autores ${ }^{8}$, con la justicia denegada, conviene advertir que el «proceso de internamiento involuntario por razón de trastorno psíquico" constituye, en particular, uno de los máximos exponentes del axioma recién expuesto. Y es que tratándose de la protección del derecho a la libertad, tal y como ha advertido nuestra moderna doctrina procesal ${ }^{9}$, la actitud jurisdiccional frente a las dilaciones indebidas ha de ser más enérgica.

El retraso injustificado en la impartición de Justicia, apreciable en este tipo de procesos, dónde se ventilan decisiones sobre derechos fundamentales de tanta trascendencia como la libertad, -cuya negativa incidencia en el ámbito vital de las personas, privándolas de esta libertad ambulatoria, con sus diversas manifestaciones e implicaciones

7 Vid., ARAGONÉS ARAGONÉS, R., cuando advierte lo siguiente: «la experiencia me ha demostrado que la mayoría de los supuestos de ingreso psiquiátrico involuntario son por razones de urgencia y la no urgencia es la excepción», «El internamiento psiquiátrico», en "Las circunstancias modificativas de la capacidad jurídica: los límites de la culpabilidad. Enfermedad mental y capacidad», Consejo General del Poder Judicial, Generalitat de Cataluña, Departamento de justicia, 2000, p. 74.

8 Vid., MUÑOZ MACHADO, S., quién afirma que «una justicia tardía equivale a una denegación de justicia en los más de los casos», en «El derecho a obtener justicia en un plazo razonable y la duración de los procesos contencioso-administrativos: las indemnizaciones debidas", Revista de Derecho Administrativo nº 25, 1980, p. 311.

9 Vid., en este sentido, GIMENO SENDRA, V., «El derecho a un proceso sin dilaciones indebidas", Jornadas sobre Derechos Humanos, Poder Judicial, número especial, CGPJ, Madrid, 1986, p. 49. 
en todos los órdenes es evidente- puede, asimismo, afectar, cuando la resolución judicial sobre su adopción se demore o se prolongue en el tiempo, más allá de un plazo razonable, de manera decisiva y gravemente perjudicial, en la persona y bienes del "enfermo psíquico", como resultado de las nefastas consecuencias, derivadas de concretas actuaciones que nunca hubiere llevado a cabo, dicho enfermo, de haber sido privado, en su debido momento, de su mal utilizada libertad.

En este sentido, resulta evidente que las actuaciones, acometidas por las personas presuntamente afectadas por trastornos psíquicos, durante el lapso de tiempo en que debiera haberse resuelto su «internamiento» -, que ocasionan perjuicios irreversibles, para sí o para terceras personas, podría haberse evitado de haberse practicado el internamiento, en su debido momento. Y esta circunstancia nos impulsa a advertir que debiera otorgarse a los «internamientos civiles involuntarios» una especial "preferencia» o "prioridad», por tratarse de una materia especialmente sensible a los "retrasos», muchas veces «justificados», debido a la «saturación» de los Juzgados y Tribunales, en la impartición de justicia.

\section{NATURALEZA}

La naturaleza del «internamiento no voluntario por razón de trastorno psíquico es, al igual que acontece con los restantes procesos sobre la capacidad de las personas, jurisdiccional, contenciosa y contradictoria.

Pese a la naturaleza eminentemente jurisdiccional, predicable de los procesos sobre la capacidad de las personas, en general, hemos de advertir, sin embargo, que el proceso de «internamiento involuntario por razón de trastorno psíquico», en particular, constituye, en buena medida, el lógico corolario jurídico de una decisión que, en puridad, merece ser calificada como médica. En este sentido, la decisión judicial, adoptada en materia de «internamiento involuntario por razón de trastorno psíquico» vendrá, en realidad, a otorgar una adecuada cobertura jurídica a una determinación técnica previa, que corresponderá, exclusivamente a los facultativos. Pese a ello, la conveniencia de que sean los Jueces y no otros «operadores jurídicos» quiénes deban, por razón de su función, "autorizar» o, en su caso, «ratificar» los internamientos civiles forzosos, originariamente resueltos por los facultativos, no merece, por obvia, mayores disquisiciones. 
El precepto 211 del Código Civil, predecesor inmediato del vigente artículo 763 de la LEC, reconducía el «internamiento involuntario por razón de trastorno psíquico» a los trámites de la jurisdicción voluntaria. El precepto 763 de la LEC establece, sin embargo, un proceso contencioso sui generis en el que el Juez, con la debida contradicción, recabará, de manera ágil, todo el material probatorio que le resulte imprescindible para resolver, sin pérdida de garantías pero con la mayor celeridad posible, sobre la conveniencia o inoportunidad del internamiento.

Aún cuando la resolución de los «internamientos civiles involuntarios» por los trámites de la jurisdicción contenciosa nos parece positiva cuando exista, entre las partes, una efectiva "contradicción», hemos de advertir, sin embargo, que su reconducción a los trámites de la jurisdicción voluntaria debiera tornarse imprescindible, tal y como expondremos con detalle más adelante, cuando la persona, supuestamente afectada por un concreto "trastorno psíquico" se encontrase en una situación de debilidad psicológica o de indigencia psíquica, de tal envergadura, que no pudiese, ni siquiera, manifestar, por sí misma, su voluntad al respecto de la privación de libertad con fines terapéuticos. Y es que no podemos hablar de «bilateralidad» cuando una de las partes, en concreto, la pasiva, no puede, de ninguna manera, posicionarse en el proceso. Nos hallamos, en tales casos, ante un proceso con una «dualidad de partes» ficticia, en el que la mayor parte de los trámites, de seguirse ordenadamente el curso del "juicio verbal» resultarían francamente inútiles, desproporcionados y, desde luego, muy costosos, tanto económica, como psicológicamente. Si el objetivo a alcanzar, con la reconducción de este peculiar proceso a los trámites de la jurisdicción contenciosa, es la dotación de concretas "garantías», siquiera fuere en el marco del propio proceso, a quién se encuentra en un estado de semi-inconsciencia o, lo que es todavía peor, de delirio absoluto, entonces debieran trasladarse aquellas "garantías" al proceso voluntario, para desterrar, con ello, los trámites superfluos o innecesarios, y dotar al nuevo proceso voluntario de internamiento por razón de trastorno psíquico, de quién realmente careciese de voluntad, además de las garantías procesales necesarias, de una celeridad adecuada, así como de una ausencia de desgaste psicológico, del propio afectado y de sus familiares, e incluso, de un menor coste económico.

El proceso de internamiento involuntario por razón de trastorno psíquico constituye, sin embargo, un proceso contradictorio, con la excepción, claro está, de que su protagonista esencial, que es el actual o potencial «interno», se halle en una situación de desequilibrio 
o perturbación psicológica tal, que no pueda mantener un discurso "contradictorio" con la posición mantenida, en dicho proceso, por el actor.

La «contradicción» constituye, en los supuestos divergentes al recién explicitado y a diferencia de lo que acontece, con carácter general, en los restantes procesos sobre la capacidad de las personas, la verdadera esencia del proceso de internamiento involuntario por razón del trastorno psíquico, toda vez que ante la prestación del consentimiento, por parte de la persona presuntamente afectada por el "trastorno psíquico", a su propio internamiento, que se traduce en la ausencia de "oposición», este proceso nunca tendría lugar.

\section{FUNDAMENTO}

El fundamento del proceso de «internamiento no voluntario por razón de trastorno psíquico" reside en la conveniencia de residenciar en manos del Estado, a través de sus órganos jurisdiccionales, el «control» sobre los internamientos involuntarios que se produzcan en nuestro país.

El proceso de internamiento no voluntario por razón del trastorno psíquico está, pues, destinado a la obtención de una resolución judicial en la que se autorice o, en su caso, se ratifique el «internamiento" actual o potencial, de una determinada persona, en un centro adecuado, con finalidad terapéutica y no, desde luego, meramente educativa $o$ asistencial.

El fundamento último de este proceso especial de «internamiento involuntario por razón de trastorno psíquico», hay que encontrarlo, a su vez, al igual que acontece con el resto de procesos sobre la capacidad de obrar de las personas, en la protección de éstas cuando pueda predicarse de ellas una presunta alteración psicológica o ausencia de la consciencia y de la voluntad.

Esta protección de las personas hipotéticamente afectadas por un "trastorno psíquico" de envergadura tal que requiera, para su rehabilitación, restablecimiento, reintegración o, de cualquier modo, reinserción a la sociedad, un «internamiento», en un centro adecuado, generalmente acompañado de un «tratamiento psiquiátrico», no constituye, por lo demás, una medida estatal de prevención, de represión, ni mucho menos de sanción. La finalidad de este tipo de «internamientos involuntarios civiles» es exclusivamente terapéutica. 
El «internamiento» de las personas afectadas por «trastornos psíquicos» evitará, es de prever, en determinadas ocasiones, la posible producción de perjuicios a terceros, con los que, de cualquier modo, se relacionen aquellas personas, eventualmente «agresivas» 0 «peligrosas», lo que podría inducir a pensar que el fundamento del "internamiento" también podría encontrarse en la "protección de la sociedad». Ello no es así1 ${ }^{10}$. La autorización o ratificación de «internamientos» amparados, exclusivamente, en la "protección de la sociedad", frente a la hipotética "peligrosidad» de determinadas personas presuntamente aquejadas por ciertos "trastornos psíquicos»" supondría la elaboración, en esta disciplina, de una teoría tan próxima a la comúnmente conocida como «Derecho Penal del enemigo", que podríamos, en esta ocasión, bautizarla como el «Internamiento civil del enemigo».

Así, pues, no cabe ninguna duda al respecto de que la «protección" de las personas presuntamente afectadas por toda suerte de «trastornos psíquicos» conllevará, paralelamente, si se accede a su «internamiento», la de la propia sociedad, pero la «autorización» o, en su caso, la "ratificación" de dicho internamiento no puede ampararse, en exclusiva, en la prevención general de los daños que pudieren ocasionar, de no ser "internadas», a la sociedad, en general, sino en su particular y exclusiva protección.

Así, pues, el «internamiento civil» no debe identificarse, a diferencia de lo que acontece con su homólogo penal, con una «humillación» ${ }^{12} \mathrm{o}$

10 Pese a ello, COBREROS MENDAZONA, E., explica que «la realidad que se oculta debajo del imbricado de relaciones sociales, económicas y jurídicas que se teje sobre los enfermos mentales internados consiste más bien en una protección del cuerpo social contra una serie de personas, los enfermos mentales, a los que a priori considera peligrosas. Este va a ser el auténtico leit motiv de la legislación positiva", en "Aspectos jurídicos del internamiento de los enfermos mentales», Revista de Administración Pública $\mathrm{n}^{\circ}$ 94, enero-abril, 1981, p. 138.

11 La valoración judicial, del «presunto trastornado, efectuada en exclusiva atención a la "protección de las personas» y con absoluta abstracción de su «peligrosidad», además, naturalmente, de la distinta causa que origina uno y otro "internamiento" son las notas que distinguen, por lo demás, este «internamiento civil», como "medida de protección», frente a los "internamientos penales", como medidas de seguridad. Para un estudio sobre la "persistencia de la peligrosidad», como fundamento para el mantenimiento de los «internamientos penales» de enfermos psíquicos, a los que se declara, por esta razón, exentos de responsabilidad criminal, tras la comisión de un delito, se remite al lector al estudio de MATEO AYALA, E., "La medida de seguridad de internamiento psiquiátrico. Su ejecución y control", , Instituto de Criminología de la Universidad Complutense, Madrid, 2004, pp. 102 y ss.

12 Y es que la vis sanatrix de la pena consiste, precisamente en la humillación, según CARNELUTTI, F., cuando advierte, que «quién no se ha adaptado a respetar el 
un "castigo» ${ }^{13}$, merced al cual se procura, curiosamente, la «reinserción" del condenado como consecuencia de la comisión de una actuación delictiva, sino que ha de concebirse como un «mecanismo de protección» de la persona, perturbada por un "trastorno psíquico», destinado, en esencia, a procurar su mejoría o restablecimiento.

El fracaso terapéutico de los «internamientos psiquiátricos», ampliamente reconocido y confirmado por múltiples investigaciones históricas ${ }^{14}$, pudo haberse debido, precisamente, a la errónea identificación del «internamiento» con el «castigo», así como a la estigmatización de este tipo de enfermos mentales ${ }^{15}$, cuando esta medida de protección de las personas debiera orientarse, precisamente, hacia su extremo opuesto, esto es hacia el restablecimiento psicológico, de quién se viere afectado, en un determinado período de su vida, por un concreto trastorno psíquico.

Y hemos de concluir este epígrafe lamentando que el mejor tratamiento jurídico-material que pueda conferirse a las causas de «internamiento», así como el más adecuado análisis jurídico-procesal que pueda ofrecerse, además de los mayores avances científicos que puedan producirse en el campo de la Psiquiatría, y aún los mejores medios materiales que puedan dispensarse a los «enfermos mentales», en el futuro, no servirán de nada si los profesionales

derecho ajeno, ve disminuido el derecho propio; quién ha querido erigirse por encima de los otros, es rebajado respecto de los otros. Tal es el fundamento de la reclusión. Empíricamente la misma aparece como una medida de aislamiento: científicamente se manifiesta como una medida de humillación», en «Principios del proceso penal», Ediciones jurídicas Europa-América, Buenos Aires, 1971, p. 331

13 Para un estudio sobre el «internamiento» como un castigo y sus problemáticas implicaciones en el orden práctico, se remite al lector a la obra de CARNELUTTI, F., «El problema de la pena», Ed. Rodamilans, Buenos Aires, 1999.

14 Vid., entre otras, MOLINARI, A., quién nos habla de la «función de depósito de marginalidad desempeñada por el manicomio», "Autobiografías de mujeres en un manicomio italiano a principios del siglo $\mathrm{xX}$ », en "Letras bajo sospecha. Escritura y lectura en centros de internamiento», Ed. Trea, Gijón, 2005, pp. 381 y 382.

15 Es por todos conocido el «olvido consciente» en que cayeron, y en ocasiones -lamentablemente. Todavía caen los «enfermos mentales», sometidos a largos períodos de internamiento u ocultación, cuando, tal y como indica MARMITT WADI, Y., los Psiquiatras reiteraban que aquello que provocaba la enfermedad era exactamente "callar»: "callar la diferencia», "calcificar lo existente», "debilitar la vida", "trabar la solución del ser", "frenar la historia", en lugar de tratar de "colocar para afuera tanta cosa guardada», de "exorcizar fantasmas del pasado, matándolos», de provocar "sensaciones catárticas», a través de la expresión oral o escrita del dolor, la tristeza, los disgustos (o sea, todo aquello que se identifica con las causas de la desgracia), la culpa por las malas acciones, en «Recreando la vida: catarsis y escritura íntima en las cartas de una paciente psiquiátrica», "Letras bajo sospecha. Escritura y lectura en centros de internamiento", Ed. Trea, Gijón, 2005, pp. 436 y 437. 
de todos estos ámbitos y la sociedad, en su conjunto, no modifica, radicalmente, su sesgada percepción de las «enfermedades mentales" como manifestaciones, reacciones, conductas o aptitudes psíquicas, en ocasiones, «escandalosas», que generan, - precisamente por desconocimiento-, miedo, temor, angustia y toda suerte de sensaciones de "vértigo», "vergüenza» o «impotencia» que dificultan, cuando no impiden o coartan completamente, las posibilidades de "estimulación" de la salud mental de aquellos enfermos que todavía, de aplicarse un "tratamiento adecuado" y efectuarse el preceptivo seguimiento, pueden ser «recuperables» para sí mismos y para la sociedad.

\section{EL OBJETO DEL PROCESO}

El objeto del proceso especial de internamiento no voluntario por razón del trastorno psíquico viene integrado por la pretensión o petición de la «autorización»o «ratificación» judicial necesaria para justificar la privación de libertad proferida, a la persona afectada por aquél trastorno psíquico, como consecuencia del internamiento practicado con fines terapéuticos.

El precepto $763.1 .^{\circ}$ de la LEC establece que «el internamiento, por razón del trastorno psíquico de una persona que no esté en condiciones de decidirlo por sí, aunque esté sometida a la patria potestad o a tutela, requerirá autorización judicial, que será recabada del Tribunal del lugar dónde resida la persona afectada por el internamiento".

La doctrina se ha venido cuestionando, en relación con este tipo de procesos, si por «internamiento involuntario por razón de trastorno psíquico» habría de entenderse el efectuado o, en su caso, el que pretendiese, potencialmente, efectuarse en un centro exclusivamente psiquiátrico, o si, por el contrario, también cabría acudir a este proceso especial para solicitar el «internamiento» en otro tipo de centros, como lo serían, a modo de ejemplo, los centros educativos, los centros residenciales para la tercera edad o los centros, en general, destinados a la atención de deficiencias psíquicas.

El factor relevante a la hora de solicitar, del Juez, la «autorización" o «ratificación» del internamiento no es, a nuestro juicio, el tipo de centro en el que deba ser, en concreto, internado ${ }^{16}$, el sujeto pasi-

${ }^{16}$ Asimismo, ha de tenerse en cuenta que el "centro" al que acude, inicialmente, la persona supuestamente afectada por un "trastorno psíquico» suele ser un Hospi 
vo de este proceso, sino la efectiva existencia de un «trastorno psíquico", de envergadura o magnitud tal que requiera, para su curación, la «necesidad de un internamiento», que, al propio tiempo, «no sea consentido" por la persona afectada.

Una vez acreditada la concurrencia de estos tres presupuestos, nos parece francamente ocioso debatir sobre si por razón de la «deficiencia o enfermedad mental" de la persona que, en un concreto período de su vida, padece, al propio tiempo, un «trastorno psíquico», o, en su caso, por el tipo de centro - geriátrico, juvenil o infantil- en el que dicha persona halla de ser internada, debamos o no acudir a otro proceso, diferente al que ahora nos ocupa, y que, por cierto, sería desconocido, pues no encontramos otra vía, al menos hasta este momento, para solicitar los «internamientos involuntarios por razón de trastorno psíquico» en centros diferentes a los psiquiátricos.

\section{CAUSAS DEL INTERNAMIENTO}

Las causas que originan la necesidad del «internamiento"son, en esencia, tres, debiendo concurrir, al igual que acontece con las de incapacitación —que son tres: así, la existencia de una «enfermedado deficiencia», "persistente», que «impide el autogobierno de la persona»-las tres, al propio tiempo.

Estas causas son, en primer lugar, la existencia de un trastorno psíquico que impide a la persona decidir por sí misma la necesidad de su propio internamiento; en segundo lugar, la efectiva conveniencia de este internamiento, como consecuencia de aquel trastorno psíquico; en tercer y último lugar, la ausencia de consentimiento.

La apreciación judicial de una de estas causas, individualmente considerada y sin la paralela estimación de la otra, no conllevará la automática autorización judicial del internamiento. Así, la existencia de un trastorno psíquico -que no tiene, en el presente caso y a diferencia del proceso de incapacitación, por qué ser "persistente», pudiendo perfectamente, ser ocasional o transitorio- sin la paralela conveniencia de un internamiento no constituye, desde luego, el objeto del proceso de «internamiento no voluntario por trastorno psíquico»,

tal, Residencia, Sanatorio o Ambulatorio general que cuenta con múltiples especialidades, así, entre otras, la correspondiente a la Psiquiatría, y tan sólo a la vista del estudio efectuado, por los facultativos, en dicho centro, será conveniente el "mantenimiento» en este lugar o, en su caso, el «traslado» a otro centro más acorde con el tratamiento que requiera el concreto y específico "trastorno psíquico» del «interno". 
toda vez que la pretensión de este tipo de procesos viene referida, precisamente, a la conveniencia del internamiento, no resultando relevantes, a estos efectos, los trastornos psicológicos que no precisan, para su curación, internamiento alguno.

La interdependencia recíproca de estas causas se muestra, si cabe, todavía más evidente en su enunciado inverso. En este sentido, la conveniencia del «internamiento» de una persona no podrá admitirse, por razones obvias, cuando no pueda predicarse, al propio tiempo, respecto de su estado psíquico, la preexistencia de un trastorno de esta naturaleza.

Ahora bien, la prestación del "consentimiento» para ser internado, efectuada por el "presunto trastornado», no siempre ha de conllevar, en sentido opuesto al recién indicado, la evitación de la celebración de este proceso, puesto que la eventual ausencia o insuficiencia de la voluntad, predicable de quién se manifiesta «favorable» a su propio internamiento, pudiera viciar de nulidad radical este consentimiento, lo que conllevaría la práctica de «internamientos» ilegales, por fraudulentos, pese al consentimiento, inicialmente prestado, por quién, efectivamente, «no se encontraba en condiciones de decidir por sí" algo tan relevante para el cuidado y protección de su propia persona.

Así, pues, la "prestación del consentimiento", para la práctica del propio internamiento, efectuado por la persona, supuestamente afectada por un "trastorno psíquico" no evitará, siempre y en todo caso, la celebración de este tipo de procesos, debiendo las partes implicadas en este "internamiento", ante la existencia de "dudas fundadas» sobre la validez del "consentimiento», manifestado por el «interno» actual o potencial, poner en conocimiento del Juez, dicho extremo, si se quiere evitar la ulterior celebración del proceso de habeas corpus ${ }^{17}$, previsto precisamente para los supuestos de "detención ilegal».

\section{A. La existencia de un trastorno psíquico}

La primera de estas causas, la existencia del trastorno psíquico, predicable de la persona que «no está en condiciones de decidir por sí

17 Para un análisis pormenorizado sobre este proceso, se remite al lector al estudio monográfico de GIMENO SENDRA, V., «El proceso de Habeas Corpus», Ed. Tecnos, Madrid, 1985. 
misma la necesidad de su propio internamiento" será objeto de valoración judicial, emitida conforme a los estudios efectuados por los especialistas al respeto.

La "ausencia de condiciones psicológicas para decidir la necesidad del internamiento", de la persona directamente afectada por el procedimiento, con independencia de su sometimiento a la patria potestad o tutela, encuentra su fundamento en la "ausencia de consentimiento" necesaria para la iniciación del proceso, toda vez que la aceptación del internamiento, efectuada por la persona, presuntamente aquejada por un trastorno psíquico, evitará la realización de un procedimiento destinado, en definitiva, a lograr una «autorización judicial» que sustituya la prestación del denominado "consentimiento informado" de la persona sometida a un tratamiento, en el que se incluye, probablemente entre otras prescripciones médicas, el «internamiento involuntario».

El trastorno psíquico que aqueja a la persona afectada, al propio tiempo, por la necesidad de este "proceso de internamiento» no ha de ser, necesariamente, "permanente», "persistente», "habitual» o, en fin, "constante», a diferencia de lo que acontece con la "enfermedad" o "deficiencia» que impide el autogobierno de las personas ya «incapacitadas» o, en su caso, de las sometidas al proceso de incapacitación, pudiendo, por el contrario, tratarse, perfectamente, de un trastorno "ocasional», «atípico», «fortuito», «accidental» o, en cualquier caso, "transitorio», «breve» $\mathrm{y}$ "pasajero».

Esta apreciación no ha de entenderse en un sentido excluyente. Así, pues, el internamiento involuntario constituye un proceso especial al que deberán someterse, tanto las personas presuntamente afectadas por una "enfermedad» o «deficiencia» persistente que las inhabilite para el autogobierno, como aquellas otras aquejadas de un «trastorno psíquico» ocasional, pasajero, breve, -como podría serlo, a modo de ejemplo, una intoxicación etílica o, incluso, una tentativa de suicidio, que requiriese, para su adecuado tratamiento, la realización del internamiento- que se encuentren, debido a ello, necesitadas, por razones de seguridad y de protección, de un «internamiento".

Ahora bien, este trastorno psíquico ha de ser de tal entidad que impida a la persona gobernarse por sí misma, si no con carácter de permanencia hacia el futuro, sí al menos en el propio momento del «internamiento».

La concreción sobre cual sea, en cada caso concreto, un «trastorno psíquico», que afecte a una determinada persona, en grado o con 
la intensidad suficiente como para estimar procedente su «internamiento» habrá de ser efectuada por los especialistas.

Así, pues, el «trastorno psíquico», al igual que la «enfermedad o deficiencia persistente que impida el autogobierno" también será objeto de "graduación», si bien la elevada incidencia del primero, en el estado de la persona, no se concretará, a diferencia de las segundas, en la determinación de los actos jurídicos que aquél pueda realizar, ni mucho menos de la institución tutelar a la que halla de quedar sometido, sino sencillamente en su «internamiento con fines terapéuticos».

Y es que de la elevada «intensidad» del trastorno psíquico, observable en la persona afectada, dependerá no sólo su inicial «internamiento", sino también su mantenimiento hasta el restablecimiento de la libertad, que vendrá dado, precisamente, con la desaparición o mitigación de los síntomas de aquél trastorno psíquico.

La noción «trastorno psíquico» constituye un concepto jurídico indeterminado que se verá integrado, en la casuística cotidiana, por las más variadas manifestaciones psico-patológicas de la personalidad ${ }^{18}$, que los Jueces y Tribunales, en estrecha colaboración con los profesionales de la Medicina, puedan detectar, analizar y, en su caso, combatir.

Las «anomalías», "rarezas» o, en fin, las manifestaciones o proyecciones de una personalidad "extravagante», "atípica» o "peculiar», dimanante de la realización de actividades originales, de la adopción de actitudes singulares o, en su caso, de la emisión de opiniones diferentes a las comunes, lógicamente, no encontrará cabida dentro de este concepto.

La noción «trastorno psíquico» es, finalmente, lo suficientemente amplia como para abarcar toda suerte de manifestaciones, desde las situaciones extremas de auténtico delirio hasta la mera ausencia o insuficiencia de una mínima o razonable "inteligencia» y "voluntad», pasando por las demencias seniles, trastornos infantiles y un sinfín de otras proyecciones, cuya apreciación, al efecto de determinar la ne-

${ }^{18}$ Para un estudio pormenorizados sobre los diferentes "trastornos psicopatológicos», entre los que se incluye, a los efectos de la valoración de la imputabilidad penal, el "retraso mental", debido a su afectación a la función psíquica "primordial", que es, según este autor, la inteligencia, se remite al lector al trabajo de MATEO AYALA, E., «La imputabilidad del enfermo psíquico: un estudio de la eximente de anomalía o alteración psíquica en el Código Penal español», Instituto de Criminología de la Universidad Complutense, Madrid, 2003, pp. 197 y ss. 
cesidad del internamiento, corresponderá al Juez, debidamente asesorado por los profesionales de otras ramas del conocimiento científico, especialmente de la Medicina.

La naturaleza, el origen o, en su caso, el desarrollo del «trastorno psíquico", que, en concreto, afecte a una determinada persona, no debe resultar, por lo demás, óbice alguno para acudir a este proceso, que está previsto, a nuestro modo de ver ${ }^{19}$, para la totalidad de trastornos psíquicos, que afectan a las personas, con independencia de cual sea, en cada caso, su concreta etiología o caracterización.

Ahora bien, de lo que no cabe duda, a nuestro juicio ${ }^{20}$, es de que el «trastorno», predicable de la persona, susceptible, por esta causa, de un «internamiento» actual o potencial, ha de ser de naturaleza, "psíquica", no debiendo incluirse, en dicha categoría, los trastornos exclusivamente físicos.

La Ley protege, en materia de «internamientos», al igual que lo hacía, en materia de "incapacitación", a las personas afectadas por una sintomatología de "presunta ausencia o deficiencia de autogobierno», y lo hace precisamente por razón de esta hipotética ausencia de «inteligencia» y "voluntad». Supondría, a todas luces, un «intervensionismo" exacerbado, el que se facultase a los Médicos, con la debida autorización de los Jueces y Tribunales, a «imponer»o, de cualquier modo, a "obligar" el internamiento involuntario de personas, perfectamente lúcidas, por enfermedades o trastornos meramente físicos.

En este sentido, la «voluntad" de la persona con suficiente capacidad natural y jurídica goza de prioridad absoluta, como es lógico, frente a los eventuales "consejos sanitarios", que se le pudiesen transmitir a la hora de someterse o no a un determinado tratamiento, y

19 Vid., JIMÉNEZ SORIA, J., quién afirma, - frente a los partidarios de la exclusiva utilización de este proceso para las «enfermedades mentales", dejando al margen de dicha consideración las "demencias seniles»-que "por encima de todas las explicaciones está la protección de las personas. Esta es la finalidad, constitucionalmente reconocida, de la actuación de todos los que intervienen en este tipo de procesos (jueces, fiscales, fundaciones tutelares, etc) y esta finalidad debe estar por encima de cualquier otra consideración más menos purista o formalista en exceso», "Ingresos en centros geriátricos», en "Revisión de los procedimientos relativos a la incapacidad», Jornadas Fundación Aequitas, Madrid, 2004, p. 216.

20 Vid., en sentido contrario, ALBÁCAR, J. L. y MARTÍN GRANIZO, M., quiénes parecen decantarse por la posibilidad de incluir las «enfermedades físicas», cuando afirman que «tan necesitado de semejante protección puede estar el hipotético enfermo mental como en enfermo somático», en "Código Civil. Doctrina y jurisprudencia», Tomo I, Ed. Trivium, 2. ${ }^{a}$ ed., Madrid, 1991, p. 211. 
ello, naturalmente, sin que quepa, en este sentido, la más mínima interferencia estatal.

Sin perjuicio de lo anterior, conviene apuntar, al igual que lo hacíamos al analizar las «causas de incapacitación», que determinadas «enfermedades» eminentemente físicas tienen, ello no obstante, claras manifestaciones, proyecciones o implicaciones en el plano psicológico de las personas. Este sería el caso, entre otros, de los pacientes afectados por un consumo "compulsivo" de alcohol o de drogas. El origen, psíquico o físico, del «trastorno psico-físico» no debiera constituir, a nuestro modo de ver, impedimento alguno a la hora de acudir a este tipo de procesos, siempre, claro está, que la persona necesitada del «internamiento» se halle, de cualquier modo, afectada, en el momento del «internamiento» por implicaciones psico-patológicas, siendo conscientes de que la recuperación de la lucidez de la persona afectada por esta sintomatología - y este tipo de estados de drogadicción o embriaguez, no se caracterizan, afortunadamente, por una larga duración- determinará la automática finalización del «internamiento indeseado».

\section{B. La conveniencia del internamiento con fines terapéuticos}

Aún cuando la necesidad del «internamiento» constituye, en ciertos casos, un complemento esencial del proceso de incapacitación, conviene advertir, ello no obstante, que ambos tipos de procesos - así, de un lado, el proceso de incapacitación y, de otro, el proceso de internamiento no voluntario por trastorno psíquico- son diferentes y autónomos.

Pese a su autonomía, a lo largo de la tramitación de un procedimiento de incapacitación, lógicamente puede presentarse la necesidad de autorizar o ratificar el «internamiento" del "presunto incapaz». En tal caso habrá de estarse, como es lógico, tanto a las normas que regulan la "incapacitación», como a las que disciplinan el «internamiento", pudiendo, perfectamente sustanciarse, ambos tipos de procedimientos, en un solo proceso.

Aún cuando el «internamiento» requerirá, para su validez, una "autorización" o, en su caso, una "ratificación" judicial, lo cierto es que la decisión sobre la «conveniencia» o «inoportunidad» de su práctica corresponderá, en realidad, a los facultativos. Esta decisión sobre la "conveniencia» del internamiento habrá de adoptarse, como consecuencia de la previa apreciación médica de un «trastorno psí- 
quico", concurrente en la persona que deba ser sometida a esta "medida de protección», con la evidenciable finalidad de procurar, por la vía terapéutica, su inmediato reestablecimiento.

De lo recién expuesto se infiere que la medida de protección de las personas consistente en su "internamiento" no cabe cuando su finalidad fuere exclusivamente asistencial, educativa o sanitaria, con el consiguiente desplazamiento de la verdadera finalidad de esta medida, que lo será, como se acaba de indicar, el restablecimiento de las personas afectadas por «trastornos psicológicos».

En este sentido, las personas aquejadas por "enfermedades", «impedimentos» o "trastornos físicos" nunca serán sometidas, como es lógico, a este proceso de «internamiento involuntario», puesto que la dependencia, exclusivamente sanitaria, terapéutica o asistencial, de estas personas requerirá su expresa conformidad. La ausencia de consentimiento de estas personas supondrá, sencillamente, la automática inactividad de los "especialistas" de las distintas ramas del conocimiento, destinados, por razón de su profesión, a «mejorar» la salud y, en su caso, las condiciones de vida de las personas ${ }^{21}$, sin que el Estado deba proteger, de modo imperativo, a estas personas. $\mathrm{Y}$ es que, con independencia de la efectiva «conveniencia de la privación de libertad con fines terapéuticos», a nadie en su sano juicio se le puede "obligar» a someterse a un determinado "internamiento" ni, en general, a un concreto "tratamiento médico».

Las personas afectadas por una "deficiencia» psíquica, tampoco serán sometidas a este "proceso de internamiento involuntario» 22 - salvo que ésta, claro está, venga, a su vez, acompañada de un "trastorno psíquico»-, puesto que el eventual internamiento en un concreto centro educativo especial, específicamente destinado "estimular» las aptitudes y facultades de la persona, no resulta coincidente, ni con el origen del trastorno requerido para la práctica del «internamiento involuntario por razón del trastorno psíquico», ni con la finalidad terapéutica que esta medida ha de cumplir.

21 Entre estos «especialistas» han de contarse los destinados a la suministrar, a las personas dependientes, una «ayuda» o «apoyo" personalizado, merced a la afortunada Ley 39/2006, de 14 de noviembre, de promoción de la autonomía personal y atención a las personas en situación de dependencia.

22 Vid., en este sentido, SÁNCHEZ-CALERO ARRIBAS, B., cuando advierte que "sería excesivo exigir a los padres de un disminuido psíquico que no puede decidir por sí, como consecuencia de su deficiencia mental, autorización judicial para internarle en un centro en el que se le vaya a dar una formación acorde a su deficiencia psíquica», en "La actuación de los representantes legales en la esfera personal de menores e incapacitados», Ed. Tirant lo blanch, Valencia, 2005, p. 97. 


\section{La ausencia de consentimiento}

La ausencia de consentimiento, como tercer requisito, constituye, en puridad, una «redundancia» $\mathrm{O}$ "reincidencia» en una idea ya apuntada anteriormente, si tomamos en consideración que la persona afectada por un «trastorno» que nos sugiere, la mayor parte de las veces, en hipótesis, una «ausencia de autogobierno» no podrá prestar, en ningún caso, válidamente su consentimiento.

Ahora bien, la «ausencia de consentimiento", pese a la redundancia descrita como consecuencia de la correlación existente entre la ausencia o insuficiencia del autogobierno y la inexistencia del consentimiento resultará, sin duda, muy útil en aquellos casos, esperemos que pocos, en los que se solicita la autorización o, en su caso, la ratificación del «internamiento» de personas perfectamente capaces y lúcidas.

Si partimos de la premisa consistente en que la «ausencia de consentimiento» constituye un requisito sine qua non de la acción de internamiento, hemos de admitir, paralelamente, el imprescindible análisis judicial de este presupuesto.

Así, pues, el Juez habrá de diferenciar, pese a las dificultades de delimitación, la "ausencia de consentimiento", predicable de las personas que no pueden prestar dicho consentimiento como consecuencia de la absoluta inexistencia de autogobierno, de aquella otra "ausencia de consentimiento", dimanante, sin embargo, de personas con suficiente capacidad de obrar. Respecto de estas personas con suficiente "capacidad de obrar", todavía habrá de discernir entre aquellas que, no obstante el reconocimiento de la capacidad de obrar, se encuentren, en ese momento, en un estado transitorio de «trastorno psíquico», de aquellas otras que carezcan del más mínimo síntoma de aquél trastorno psíquico, no resultando procedente, en este último supuesto, la autorización del internamiento.

Si el Juez detectase, en este concreto proceso, que la "persona», afectada por la solicitud de "autorización" o «ratificación" del internamiento, además de dar muestras palmarias de un concreto trastorno psíquico, parezca aquejada, al propio tiempo, por una «enfermedad» $\mathrm{o}$ "deficiencia», persistente y grave, que la inhabilite para el autogobierno, entonces, lógicamente, además de autorizar o, en su caso, ratificar el internamiento, habrá de poner el hecho en conocimiento del Ministerio Fiscal para que promueva la oportuna acción de incapacitación. 
Conviene, finalmente, admitir, con independencia de la opinión que nos merezca el análisis e interpretación de este presupuesto, que la «ausencia de consentimiento» es el factor determinante a la hora de reclamar la intervención judicial, toda vez que si el «paciente» acepta, consiente o informa positivamente a la sugerencia efectuada por los Médicos sobre la conveniencia de la adopción, con fines terapéuticos, de la medida consistente en su internamiento, entonces, salvo que se apreciase la existencia de "vicios del consentimiento», no habrá lugar a la celebración de un proceso contradictorio.

El Juez habrá de acometer, en síntesis, la difícil tarea de averiguar si la persona "presuntamente» afectada por un "trastorno psíquico" carece de voluntad, y, por tanto el proceso habrá de suscitarse con independencia de cual sea su preferencia - favorable o contraria- hacia la puesta en práctica del internamiento, o, por el contrario, goza de suficiente voluntad y, en consecuencia, el proceso tan sólo se suscitará ante su «oposición» manifiesta, clara, inequívoca y expresa, frente a dicho «internamiento», pudiendo tan sólo prescindirse de la realización de aquél proceso cuando esta persona mostrase, en el caso contrario al recién expuesto, su conformidad.

La "prestación del consentimiento", efectuada por el paciente presuntamente aquejado por un "trastorno psíquico», como medida imprescindible para la adopción de su internamiento, sin necesidad de "autorización» o "ratificación» judicial — habida cuenta de la naturaleza contractual predicable de toda vinculación existente entre los Médicos, en el marco de su profesión, y sus pacientes- no habrá de identificarse con una "manifestación expresa de la voluntad inequívoca de ingresar y permanecer en el centro de internamiento, con fines terapéuticos, todo el tiempo que resulte necesario", bastando, a tales efectos, a nuestro juicio, el «mero asentimiento" o, cuando menos, la ausencia de una concluyente y manifiesta «oposición». Nos parece, en este sentido, que la generalización de la opción contraria constituye una injustificada medida de proliferación de juicios innecesarios.

Y ello es así debido a la circunstancia de que si se precisase la «autorización" o "ratificación», como parece pretender nuestra Ley, siempre y en todo caso, de quiénes, debido a su completa enajenación mental o padecimiento momentáneo de un instante de delirio, careciesen del más mínimo raciocinio, sin conocer en absoluto cual sería su «voluntad», favorable o contraria, frente al internamiento, en un momento ulterior, entonces se estaría fomentando la promoción de juicios, probablemente inútiles, sobre la presunción de la «oposición» al internamiento. 
Lógicamente la «autorización» o «ratificación» judiciales han de ser, en caso de duda sobre la validez del consentimiento, la regla general de todo internamiento, frente a la excepcionalidad del efectuado sin tales resoluciones judiciales, pero ello no debe llevarse al extremo de exigir la celebración de un juicio para todos y cada uno de los casos de inexistencia -que no de oposición - de consentimiento como consecuencia de la situación de radical desconexión con la realidad, predicable del enfermo mental.

La «recuperación de una mínima lucidez» de quién ya se encuentre «interno» determinará, por lo demás, en caso de «oposición frontal a su internamiento», la necesidad de la "ratificación judicial» de esta medida de protección para el mantenimiento de aquella situación. Si este paciente, al recuperar la facultad, cuando menos, de la comunicación, no manifiesta, con claridad, su «contrariedad» para con el «internamiento», entonces no encontramos razón para la celebración de un juicio que, a buen seguro, perturbará al enfermo y no mejorará, en nada, la situación en la que se encuentra.

$\mathrm{La}$ «ausencia de consentimiento» no podrá ser sustituida, en los casos en que la persona afectada por la medida terapéutica restrictiva de su libertad estuviere, al propio tiempo, sometida a alguna institución tutelar, por la «aceptación» de quién ejerciese la patria potestad o la tutela.

Esta "ausencia de consentimiento", inicialmente detectada, habrá de perdurar, por lo demás, a lo largo de todo el tiempo de duración del concreto internamiento, puesto que si el paciente manifestase, durante su "permanencia" en el centro de que se trate, una actitud favorable al ingreso, entonces el proceso perdería su contradicción y, con ella, su razón de ser, a salvo, claro está, de los supuestos en que dicha "voluntad favorable al internamiento» se hallase, de cualquier modo, viciada, conllevando la terminación del proceso, en tal caso, el mantenimiento de una «retención ilegal».

Si una persona ya «internada» lo fue, en el momento en el que se procedió al internamiento, por su propia voluntad o, cuando menos, sin oponer resistencia, de dónde se infirió la prestación inicial de su "consentimiento», pero a lo largo de su permanencia en el centro se opone, en cualquier momento, a este «internamiento», entonces parece razonable que deba promoverse, en ese mismo momento, el proceso destinado a obtener la «ratificación» judicial del internamiento.

Finalmente, hemos de reiterar, a modo de síntesis, que la «ausencia de consentimiento" constituye un requisito absolutamente im- 
prescindible para la celebración, de principio a fin, de este tipo de procesos, toda vez que la reivindicación, de la que ahora nos hacemos $\mathrm{eco}^{23}$, de la "autorización judicial» de «internamientos voluntarios» nos parece una pretensión que excede, a todas luces, la protección de las personas, para instalarse, de plano, en la necesidad de un excesivo paternalismo o sobre-proteccionismo estatal.

\section{LOS SUJETOS DEL PROCESO}

El proceso de internamiento involuntario por razón de trastorno psíquico, no obstante el evidente "relativismo» del principio dispositivo predicable de su tramitación, tan sólo podrá iniciarse, al igual que acontece con los restantes procesos sobre la capacidad de las personas, a instancia de parte, sin que en ningún caso pueda instarse de oficio.

\section{LEGITIMACIÓN ACTIVA}

El precepto $762.1 .^{\circ}$ II de la LEC establece que «la autorización será previa al internamiento, salvo que razones de urgencia hicieren necesaria la adopción de la medida. En este caso, el responsable del centro en que se hubiere producido el internamiento deberá dar cuenta de éste al Tribunal competente lo antes posible y, en todo caso, dentro del plazo de veinticuatro horas, a los efectos de que se proceda a la preceptiva ratificación de dicha medida, que deberá efectuarse en el plazo máximo de setenta y dos horas desde que el internamiento llegue a conocimiento del Tribunal».

La LEC se limita a indicar, en el precepto recién trascrito, la obligación, del responsable del centro médico, generalmente psiquiátrico, de poner en conocimiento del Tribunal, el "internamiento" ya practicado, en los supuestos de «ratificación», pero no regula, al propio tiempo, la legitimación para solicitar la «autorización judicial»al efecto de proceder al «internamiento» en un momento ulterior.

${ }^{23}$ Vid., como exponente de esta "reclamación", RAMOS CHAPARRO, E., quién ha advertido que «el ingreso voluntario sin control judicial puede resultar una puerta abierta al fraude de Ley por parte de los familiares o del personal Médico, que, aprovechando la debilidad mental del enfermo, le obliguen a sufrir una resolución aparentemente consentida, pero realmente impuesta, en la que no existirá la posibilidad de un alta voluntaria, que es siempre el corolario lógico de esta forma de internamiento», en "El internamiento de incapaces presuntos», Revista General de Jurisprudencia y Legislación n. ${ }^{\circ}$, septiembre, 1988, p. 495. 


\section{A. Solicitud de la «autorización judicial para el internamiento»}

Ante la laguna legal existente en nuestra legislación procesal, a propósito de la legitimación en este concreto proceso de «internamiento», la doctrin ${ }^{24}$ ha manifestado, de manera prácticamente unánime, que la legitimación activa para solicitar la autorización judicial previa al internamiento corresponde, en aplicación de la analogía, a los legitimados para la promoción del proceso de incapacitación.

Así, pues, la legitimación activa para promover la acción de internamiento involuntario por razón de trastorno psíquico corresponderá, indistintamente, al "hipotético trastornado», al cónyuge o a quién se encuentre en una situación de hecho asimilable, a los descendientes, a los ascendientes, a los hermanos y, en su caso, aunque la $L E C$ no se refiera a estas personas en su regulación de la «legitimación activa para promover el proceso de incapacitacion»-al tutor o curador de la persona presuntamente aquejada por aquél trastorno psíquico.

Si estas personas no existiesen o, de existir, no hubiesen solicitado el internamiento, entonces corresponderá la incoación de este proceso al Ministerio Fiscal, que habrá tenido conocimiento de esta noticia bien por «cualquier persona»-recuérdese, en este momento, la facultad, que corresponde a todos los ciudadanos, de poner en conocimiento del Ministerio Fiscal, los hechos que puedan ser determinantes de la «incapacitación» y que, si los trasladamos a este proceso, lo serian del «internamiento»-, o bien por las autoridades y funcionarios públicos —obligados a poner estos hechos en conocimiento del Ministerio Fiscal - que hubieren tomado, asimismo, conocimiento de la existencia de la persona, afectada por un "trastorno psíquico», que precisa ser internada, por razón de su cargo o de su función.

Si la persona presuntamente afectada por un «trastorno psíquico», a la que resultase conveniente, para su restablecimiento, un «internamiento», estuviere sometida, al propio tiempo, a tutela ${ }^{25}$ o curate-

${ }^{24}$ Vid., en este sentido, DÍEZ-PICAZO GIMÉNEZ, I. (con DE LA OLIVA, A. y VEGAS TORRES, J., "Derecho Procesal Civil. Ejecución forzosa. Procesos especiales», Ed. CEURA, Madrid, 2000, p. 430; GIMENO SENDRA, V. y MORENILLA ALLARD, P., «Derecho Procesal Civil», volumen II, «Los procesos especiales», Ed. Colex, 1. a ed., Madrid, 2005, p. 263.

${ }_{25}$ Se recuerda al lector que el precepto $271.1^{\circ}$ del Código Civil establece que «el tutor necesitará autorización judicial para internar al tutelado en un establecimiento de salud mental o de educación o formación especial». 
$\mathrm{la}^{26}$, entonces, la legitimación para solicitar la «autorización» corresponderá, como es lógico, al tutor o curador.

El propio afectado por la «medida de internamiento» también puede solicitar, del Juez, la "autorización» para su propio internamiento, pero, en tal caso, el proceso no tendría razón de existir, toda vez que la "petición de internamiento», efectuada por el "presunto trastornado» revelaría, en verdad, la "prestación de consentimiento» para su internamiento, de dónde se infiere que la "autorización judicial» -que viene, en puridad, a suplir la "ausencia de consentimiento»- ya no sería necesaria.

La legitimación activa para solicitar el «internamiento por razón de trastorno psíquico» de los menores corresponderá, sin embargo, a quiénes ejerzan la patria potestad o tutela. Las mismas razones que nos impulsaron a advertir que debiera regularse una legitimación más amplia para la promoción de la incapacitación de los menores, resultan igualmente válidas para afirmar la necesidad de una legitimación extensiva, cuando menos, a los familiares más próximos y, desde luego, al Ministerio Fiscal, para solicitar el «internamiento por razón de trastorno psíquico de los menores".

\section{B. Solicitud de la «ratificación judicial para el internamiento»}

Cuando, por razones de urgencia, el internamiento ya se hubiere producido, sin una autorización previa, entonces, según indica el precepto $763.1 .^{\circ} \mathrm{II}$, el responsable del centro en que se hubiere producido el internamiento deberá dar cuenta de éste al Tribunal competente lo antes posible y, en todo caso, dentro del plazo de veinticuatro horas, a los efectos de que se proceda a la preceptiva ratificación de dicha medida, que deberá efectuarse en el plazo máximo de setenta y dos horas desde que el internamiento llegue a conocimiento del Tribunal.

La legitimación para solicitar la ratificación judicial del internamiento, una vez haya sido practicado corresponderá al responsable del centro dónde se hubiere producido el internamiento,

26 Salvo que la sentencia judicial de «incapacitación» disponga expresamente otra cosa, al curador le será aplicable el precepto enunciado en la nota anterior, toda vez que el artículo 290 del Código Civil determina que «si la sentencia de incapacitación no hubiere especificado los actos en que deba ser necesaria la intervención del curador se entenderá que ésta se extiende a los mismos actos en que los tutores necesitan, según este Código, autorización judicial». 
El precepto $763.1 .^{\circ}$ III de la LEC determina que «el Tribunal deberá actuar conforme a lo dispuesto en el precepto $757.3 .^{\circ}$ de la misma Ley», dónde se establece que "las autoridades y funcionarios públicos que, por razón de sus cargos, conocieran la existencia de una posible causa de incapacitación en una persona, deberán ponerlo en conocimiento del Ministerio Fiscal».

De lo anterior se infiere que el Juez correspondiente al lugar en que radique el centro dónde se hubiere producido el internamiento deberá poner en conocimiento del Ministerio Fiscal, la existencia de la persona que ha sido internada, de manera involuntaria, por razón de un trastorno psíquico. El Juez, ante la "puesta en conocimiento» del internamiento, efectuada por el responsable del centro, habrá de pronunciarse, asimismo, en el plazo máximo de setenta y dos horas, sobre la ratificación o no del internamiento practicado.

Esta extraña legitimación, predicable del responsable del centro psiquiátrico, que más parece una «obligación", para "poner en conocimiento" del Juez, la práctica de un internamiento, que, a su vez, habrá de ser puesto, por este mismo Juez, en conocimiento del Ministerio Fiscal, con el objeto de que éste se ocupe, al fin, de ostentar la cualidad de «legitimado activo" en el ulterior proceso destinado, en su caso, a la incapacitación supone, tal y como puede observarse a primera vista, un enredo.

El responsable del centro no podrá limitarse, en su solicitud de «ratificación» del internamiento practicado, a poner este «internamiento" en conocimiento del Juez -como si de la facultad de poner en conocimiento del Ministerio Fiscal la notitia incapacitationis se tratase- debiendo especificar, en su escrito, no sólo los datos de identificación del interno y las concretas circunstancias en las que se encontraba cuando fue atendido, sino también el concreto trastorno psíquico que le aqueja, e incluso el sometimiento al tratamiento que resulte más adecuado para la superación de dicho trastorno, de manera conjunta a la previsión sobre su pronóstico en el futuro.

Aún cuando la LEC se refiere, al objeto de la determinación de las personas, en concreto, obligadas a «solicitar la ratificación del internamiento", en exclusiva, al responsable del centro psiquiátrico dónde éste se hubiere producido, ello no obsta, como es lógico, para que las personas legitimadas para promover la «autorización» del internamiento, a las que nos hemos referido en el capítulo precedente, $-y$ que son, recordemos, el cónyuge o quién se encuentre en una situación de hecho asimilable, los descendientes, los ascendientes, los hermanos y, en su caso, los tutores o curadores de la persona presuntamente aque- 
jada por el trastorno psíquico- puedan instar, cuando el internamiento ya se hubiere producido, si lo estiman pertinente, su oportuna «ratificación».

\section{LEGITIMACIÓN PASIVA}

Este peculiar proceso de internamiento involuntario por razón de trastorno psíquico tiene por destinatarias, tanto a las personas que hayan sido «incapacitadas», tras la celebración del proceso de incapacitación; como a las "presuntas incapaces», que se encontrasen, en el momento del «internamiento», en alguna fase o período procesal de aquel procedimiento de incapacitación, e incluso, a las plenamente capaces. Y ello es así debido a la circunstancia, que ya hemos evidenciado en otro epígrafe de este trabajo, de que las «causas» que motivan la promoción la «incapacitación» enfermedad o deficiencia persistente que inhabilita para el autogobierno- y del «internamiento» -trastorno psíquico - tienen una particularidad común -la ausencia o insuficiencia de raciocinio como consecuencia de una patología psicológica-, pero no son idénticas, pudiendo, desde luego, suceder que una persona perfectamente lúcida y consciente, en su vida cotidiana, pierda, durante una etapa de ésta, aquella lucidez, sin que, por ello, sea preciso «incapacitarla».

La legitimación pasiva corresponde, lógicamente, aunque nada diga la LEC al respecto, a la persona afectada por la medida del internamiento no voluntario por razón del trastorno psíquico.

Esta persona podrá comparecer en el proceso, como es lógico, con su propia defensa y representación, debiendo resultar aplicables, por analogía, ante la ausencia de regulación legal expresa al respecto, las normas generales de la «incapacitación». Así, pues, la persona supuestamente afectada por un trastorno psíquico podrá comparecer, en el proceso de internamiento involuntario, con su propia defensa y representación, debiéndosele, incluso, tal y como se ha previsto ${ }^{27}$, designar, si así lo solicitase, un Abogado de oficio. Si esta persona careciese de Abogado y Procurador designados por sí mismo, habrá de acudir al proceso con la oportuna defensa del Ministerio Fiscal, salvo

${ }^{27}$ Vid., al respecto, DOLZ LARGO, M. J., quién, asimismo, opina que «hay que huir del paternalismo fácil que supone entender cubiertas las garantías del presunto incapaz por la intervención del Estado (Jueces y Fiscales) cuando la persona afectada pretende ser defendida por un Abogado», en «El internamiento psiquiátrico civil en España: Aspectos legales», Justicia, IV, 1992, p. 895. 
que éste hubiere sido el promotor del proceso, en cuyo caso se le designará un defensor judicial.

\section{PROCEDIMIENTO}

Los antecedentes inmediatos a la actual regulación, en la LEC $1 / 2000$, del «internamiento involuntario por razón de trastorno psíquico», podemos encontrarlos en el Real Decreto de 19 de mayo de 1885 y en el Decreto de 3 de julio de $1931^{28}$ —dónde se regulaban tres tipos de internamientos: los voluntarios, los efectuados por prescripción médica y los autorizados por orden gubernativa, adoptados a través de procedimientos administrativos, dónde la supervisión o control judicial estaba residualmente orientada hacia la depuración de eventuales responsabilidades - y la Ley 13/1983, de 24 de octubre, que introduce un nuevo proceso en el precepto 211 del Código Civil, actualmente derogado por nuestra vigente Ley Procesal Civil y la LO 1/1996, de 15 de enero, que otorgó una nueva redacción al precepto recién indicado.

Aún cuando la introducción, en una norma de contenido sustantivo, de un procedimiento no debe ser calificada como plausible, lo cierto es que la regulación del proceso de «internamiento involuntario por razón de trastorno psíquico", en el Código Civil, mereció una inmejorable acogida, puesto que al fin esta medida de protección de las personas consistente en su "privación de libertad» sería adoptada, en el orden civil, con las debidas garantías, por los Jueces y Magistrados integrantes del Poder Judicial.

A pesar de que la constitucionalidad de la regulación, en una norma de naturaleza ordinaria, de la privación involuntaria de libertad, para el internamiento en centros psiquiátricos, por razones de trastorno psíquico, fue, en su momento, puesta en cuestión ${ }^{29}$, el Tribunal

${ }^{28}$ Para un estudio pormenorizado sobre la evolución del tratamiento sustantivo y procesal de los «internamientos» practicados en España, con anterioridad a la regulación contenida en el derogado artículo 211 del Código, introducido por la Ley $13 / 1983$, de 24 de octubre, precedente inmediato de nuestro vigente precepto procesal civil 763, se remite al lector a la obra de BERCOVITZ RODRIGUEZ-CANO, R., "La marginación de los locos y el Derecho», Ed. Taurus, Madrid, 1976.

${ }^{29}$ En la STC 129/1999, de 1 de julio, r. 129, famosa en esta materia, se entabló una cuestión de constitucionalidad, que no prosperó, frente al precepto 211 del Código Civil, en la que el órgano judicial sospechó que aquella norma podría adolecer de un vicio de constitucionalidad de naturaleza formal, habida cuenta de que, en su opinión, el precepto cuestionado debería revestir la forma de ley orgánica, por así resultar de las exigencias derivadas de los arts. 17.1 y 81.1 de la Constitución. El TC estimó, frente a esta sospecha, que las garantías procedimentales contenidas en este 
Constitucional estimó que el procedimiento de adopción de la decisión judicial de internamiento encuentra un desarrollo conforme, de un lado, con las exigencias derivadas del artículo 17 de la CE y, de otro, con los derechos fundamentales reconocidos en los dos apartados del precepto 24 de la $\mathrm{CE}$. Y ello debido a que este proceso de «internamiento involuntario por razón de trastorno psíquico» asegura la audiencia de la persona afectada, hace posible su oposición al internamiento y concluye con una autorización de naturaleza transitoria necesariamente revisable en plazos de tiempo razonables y sólo adoptada tras haberse acreditado, mediante la práctica de pruebas oportunas y tras oír el dictamen de, al menos, un facultativo, que la medida de internamiento aparece como la más conveniente en beneficio del propio afectado y de la comunidad.

La ausencia de referencia expresa, en nuestra LEC, al tipo de proceso que, en concreto, ha de guiar el procedimiento de internamiento desde la petición inicial de su «autorización» o, en su caso, de su "ratificación» judicial hasta la sentencia, unida a la imperiosa necesidad, predicable de esta última pretensión, de que la resolución judicial se produzca en un plazo máximo de setenta y dos horas-que imposibilita la remisión, por analogía respecto de la promoción de la incapacitación, al juicio verbal - ha impulsado a un primer sector de nuestra doctrina moderna ${ }^{30}$ a secundar una «libertad total de forma» siempre y cuando, claro está, se cumplan los trámites exigidos por el único precepto legal destinado a este peculiar proceso de internamiento no voluntario por razón del trastorno psíquico.

Esta ausencia de referencia expresa, en el precepto 763 de la LEC, destinado a su tramitación, a cual sea el procedimiento adecuado, ha impulsado, sin embargo, a un segundo sector de nuestra doctrina moderna $^{31}$, a estimar que dicho procedimiento lo sea el juicio verbal, en cumplimiento de la declaración general contenida en el precepto 753

precepto no constituían, a los efectos de la reserva de ley orgánica del art. $81 \mathrm{CE}$, desarrollo del derecho fundamental a la libertad personal del art. $17 \mathrm{CE}$.

30 Vid., entre otros, DÍEZ-PICAZO GIMÉNEZ, I., quién ha señalado que se inclina por pensar que «el Tribunal puede seguir el procedimiento que estime conveniente», ( con DE LA OLIVA, A. y VEGAS TORRES, J., «Derecho Procesal Civil. Ejecución forzosa. Procesos especiales», Ed. CEURA, Madrid, 2000, p. 431.

31 Vid., en este sentido, GIMENO SENDRA, V. y MORENILLA ALLARD, P., quiénes reconocen, ello no obstante, que la tramitación para la pretensión de ratificación del internamiento ya producido es aún más singular, pues la actividad probatoria habrá de realizarse en el plazo máximo de 72 horas a contar desde que «el internamiento llegue a conocimiento del Tribunal», plazo máximo que coincide con el de la detención preventiva no judicial previsto en el art. 17.2 CE», en «Derecho Procesal Civil», volumen II, «Los procesos especiales», Ed. Colex, 1ª ed., Madrid, 2005, p. 265. 
de la LEC. Este precepto dispone que "salvo que expresamente se disponga otra cosa, los procesos a que se refiere este título se sustanciarán por los trámites del juicio verbal, pero de la demanda se dará traslado al Ministerio Fiscal, cuando proceda, y a las demás personas que, conforme a la Ley, deban ser parte en el procedimiento, hayan sido o no demandados, emplazándolos para que la contesten el plazo de veinte días, conforme a lo establecido en el artículo 405 de la presente Ley».

La determinación de cual sea, en concreto, el procedimiento aplicable para los «internamientos involuntarios por razón de trastorno psíquico» corresponderá, pues, en cada caso, a nuestros Jueces y Tribunales, que podrán autorizar, por los trámites del juicio verbal, los internamientos «menos urgentes» y habrán de «ratificar», sin acudir a dicha tramitación y con plena «libertad formal», los ya producidos, si pretenden, al propio tiempo, cumplir el mandato, estipulado en el precepto $763.1 .^{\circ}$ II, de las 72 horas siguientes al momento en que la noticia del internamiento hubiere llegado a su conocimiento.

De lo que no cabe duda es de que el procedimiento previo a la adopción de la resolución en virtud de la cual se autoriza o, en su caso, ratifica un «internamiento involuntario por razón de trastorno psíquico», revestirá la forma de "procedimiento contencioso»"

Esta opción no nos parece, sin embargo, la más acertada, puesto que razones de "utilidad», «urgencia», "agilidad», «eficacia», "elasticidad» $\mathrm{y}$ «flexibilidad», sin pérdida de garantías, nos impulsan a afirmar la conveniencia de reconducir este tipo de procesos, cuando no hubiere «oposición real», a los trámites de la jurisdicción voluntaria ${ }^{33}$, como institución destinada, precisamente, según el mayor especialista en la materia ${ }^{34}$, a resolver supuestos en los que el justiciable

32 En sentido contrario, vid., sin embargo, LETE DEL RÍO, J. M., quién entiende que no se trata de un proceso constitutivo jurisdiccional, sino de un mero expediente de jurisdicción voluntaria», en «Internamiento por razón de trastorno psíquico», Actualidad Civil n. ${ }^{\circ} 43,18$ a 24 de noviembre, 2002, p. 1315.

${ }^{33}$ Vid., FERNÁNDEZ DE BUJÁN, A., quién nos advierte sobre la conveniencia de que «la autorización judicial para el internamiento de personas que padecen trastornos psíquicos se tramite a través de un procedimiento de jurisdicción voluntaria habida cuenta de la solicitud, efectuada a este respecto, nada menos que por el Comité español de representantes de personas con discapacidad (CERMI)», en "Observaciones al Proyecto de Ley de Jurisdicción voluntaria de octubre de 2006 (I)", RJE la Ley, n. ${ }^{\circ}$ 6599, 28 de noviembre de 2006, p. 10.

${ }_{34}$ Vid., en este sentido, FERNÁNDEZ DE BUJÁN, A., "Jurisdicción voluntaria», Tribuna del Diario ABC, 5 de enero de 2007, p. 68. 
debe percibir de manera directa que se hace efectivamente justicia, en atención a la brevedad, simplificación, concentración e inmediatez en la tramitación del procedimiento.

Por "oposición real» ha de entenderse la manifestada por la persona que, estando "presuntamente afectada por un trastorno psíquico», puede mostrar, a juicio del Juez, su «disconformidad» con la petición de su internamiento, de una manera razonable.

Así, pues, los supuestos en los que el «presunto trastornado» se hallase en condiciones de "negarse», con un mínimo razonamiento coherente o diálogo razonable, a su «internamiento», deberán, sin ninguna duda, sustanciarse por los trámites de un procedimiento "contencioso", ya sea a través del juicio verbal, -cuando el estado de la persona permita, debido a la ausencia de inminencia, su desarrollo; ya sea con "plena libertad formal», —cuando la «urgencia» y la "gravedad» del caso así lo aconsejen-.

Ahora bien, la reconducción del "proceso de internamiento involuntario por razón de trastorno psíquico», cuando la ausencia de «lucidez», de "entendimiento" y hasta de "consciencia», del sujeto pasivo sea evidente, a los trámites del juicio verbal con especialidades, constituye un atraso. Su tramitación por los cauces de la jurisdicción voluntaria, como si de una «autorización judicial de los tratamientos no voluntarios de las personas con trastornos psíquicos» se tratase, ganaría, desde luego, en «agilidad», "flexibilidad», "celeridad» y «transparencia», sin causar el menor menoscabo en las garantías procesales, habida cuenta de la siempre abierta posibilidad de reconducir este proceso voluntario a la vía contenciosa si, a lo largo del primer procedimiento se evidenciase una efectiva "contradicción», "oposición» o "conflicto real de voluntades".

El procedimiento a seguir, en cualquier caso, para la práctica de los «internamientos involuntarios por razón de trastorno psíquico» no variará, _-si nos atenemos a su "reconducción" automática a los trámites del juicio verbal-, en función de cual sea la pretensión, de «autorización" o "ratificación», de ese concreto internamiento, debiendo regirse ambos tipos de procedimientos, por las mismas normas procesales, con una única particularidad en materia de prueba, en concreto, la referida al dictamen del facultativo, de la que nos ocuparemos en su momento. 


\section{INTERPOSICIÓN DE LA PRETENSIÓN}

La iniciación del proceso será, con carácter general, a instancia de parte. Ahora bien, ello no obsta para que el Juez inicie el procedimiento ${ }^{35}$, cuando llegue a su conocimiento, a través de una comunicación, más o menos formal, la existencia de la persona presuntamente afectada por un «trastorno psíquico».

La pretensión de internamiento puede ser actual o potencial. En este sentido, los legitimados para solicitar el «internamiento» habrán de efectuar, con carácter general, esta petición, al igual que acontece en la generalidad de procesos civiles, en el momento en el que estimen conveniente, la actuación del Estado, a través del ejercicio de la Jurisdicción, que, mediante el instrumento del proceso, ha de concretarse en el correlativo momento en el que se precisa una autorización judicial para la aplicación, a una determinada persona, aquejada por un trastorno psíquico, de aquella medida restrictiva de su libertad, con efectos beneficiosos para ella.

Ahora bien, cuando especiales razones de urgencia hubieren aconsejado la práctica de dicho internamiento, en un momento anterior a la incoación del proceso especial en el que, generalmente, se autoriza esta medida, entonces habrá de solicitarse, por razones obvias, no ya la «autorización» del internamiento que ya ha sido efectuado, si no su "ratificación» al objeto de la obtención de un «pronunciamiento judicial» sobre la conveniencia del mantenimiento de dicha medida o, en otro caso, sobre su alzamiento inmediato.

La pretensión de «autorización» o de "ratificación» del internamiento, cuya interposición corresponde a los legitimados activos, a los que nos hemos referido en el capítulo precedente, contendrá, al menos, la «identificación» de la persona, en concreto, afectada por el "trastorno psíquico", con explicación suficientemente detallada de los síntomas que aquejan a esta persona.

35 Vid., SANCHO GARGALLO, I., cuando afirma que «el Juez puede acordar el internamiento de oficio, si llega a tener conocimiento del hecho por cualquier medio. Si el internamiento acordado como medida cautelar dentro del procedimiento de incapacitación puede acordarse de oficio, nada impide que este ingreso al margen de la incapacitación también pueda acordarse de oficio, sin perjuicio de la comunicación al Ministerio Fiscal para que solicite en su caso la incapacitación", en AA. VV., "Comentarios a la nueva Ley de Enjuiciamiento Civil», coordinados por FERNÁNDEZBALLESTEROS, M. A., RIFÁ SOLER, J. M. y VALLS GOMBÁU, J. F., Ed. Atelier, 1. ${ }^{a}$ ed., Barcelona, 2000, p. 3473. 
La "solicitud» de la «autorización» o, en su caso, de la "ratificación" del internamiento no voluntario por razón de trastorno psíquico podrá, asimismo, venir acompañada de la paralela "petición» de autorización del «tratamiento», también «involuntario»y "por razón de trastorno psíquico».

La posibilidad de acumular ambas pretensiones en una única «demanda", "solicitud" o, de cualquier modo, "petición" de tutela judicial, resultará, a todas luces, muy conveniente, toda vez que la eventual dejación de la pretensión atinente al «tratamiento médico», que deba recibir el paciente durante su internamiento, para un momento ulterior, - en el que, por cierto, habría ya de canalizarse por los trámites de la jurisdicción voluntaria-, supone, sin lugar a dudas, un atraso.

La «autorización judicial del tratamiento médico» constituirá, por lo demás, una necesidad frecuente en este tipo de procesos en los que los sujetos pasivos sufren, siempre y en todo caso, - salvo, claro está, la eventual y esperemos que atípica interposición de pretensiones fraudulentas - un «trastorno psíquico» que precisará, por lo general, para su mejoría, el sometimiento a algún tipo de medicación.

La solicitud de «autorización» para el internamiento habrá de venir referida, según se ha manifestado ${ }^{36}$, al concreto y específico «centro» en el que se producirá este internamiento, debiendo referirse la resolución judicial que, finalmente, «autoriza» el internamiento, uti singuli, a ese centro determinado, lo que obligará a promover este proceso, en el supuesto de que se produzca algún traslado del paciente, tantas veces cuántas sean las que cambie, este paciente, de centro de internamiento. Esta medida - excesivamente rigurosa, a nuestro juicio- disuadirá, a buen seguro, la frecuente práctica de traslados de los «enfermos psiquiátricos», de unos centros a otros, y ello no garantiza, necesariamente, su mejor atención o tratamiento. Es por ello por lo que no podemos secundar esta postura, y hemos de advertir la conveniencia de la práctica de cuántos «traslados» sean necesarios para la mejoría de la persona todavía afectada por el trastorno psíquico, sin que ello suponga, necesariamente, la realización de nuevos procedimientos, sino simplemente la «supervisión» y «control» judicial del "internamiento» practicado, a lo largo de todo el tiempo en el que éste dure.

36 Vid., en este sentido, PERDIGUERO BAUTISTA, E., quién afirma que «las condiciones materiales y personales del centro pueden jugar en ocasiones un papel determinante para la concesión o no de la autorización», en «El internamiento por razón de trastorno psíquico tras la ley orgánica 1/1996, de protección jurídica del menor», RJE La Ley n. ${ }^{\circ} 4069,1996-3$, p. 1449. 


\section{A. Juzgado competente}

La competencia variará en función del tipo de petición solicitada en el concreto proceso de internamiento no voluntario por razón de trastorno psíquico, así la autorización para proceder a la práctica de este internamiento o, en su caso, la ratificación del internamiento ya efectuado.

El Juez competente para pronunciarse sobre la petición de internamiento no voluntario por razón de trastorno psíquico, cuando dicha pretensión fuere previa al momento del internamiento, y por tanto lo fuere de solicitud de «autorización judicial» para proceder a poner en práctica este internamiento, lo será el del lugar dónde resida la persona afectada. Sin embargo, el Juez competente para conocer de las pretensiones de "ratificación" del internamiento que, por razones de urgencia, ya hubiere sido practicado, lo será el del lugar en que radique el centro dónde se haya producido aquel internamiento.

La elección del fuero territorial ha sido, como puede vislumbrarse a primera vista, efectuada en atención al criterio de la «proximidad geográfica». En este sentido, la competencia vendrá determinada por la cercanía, del Juez competente, al lugar en el que se encuentre la persona, presuntamente aquejada por algún trastorno psíquico, que precise, para su mejoría, un internamiento.

El Juez competente para la adopción de la resolución en la que se "autoriza» o "ratifica» un determinado internamiento será, conforme al principio de la perpetuatio iurisdictionis ${ }^{37}$, el competente para efectuar el control de ese concreto internamiento durante todo el tiempo que dure, con independencia de que se produjese un cambio, por las circunstancias que fueren, del hospital o residencia inicial del internamiento a otro centro, ubicado en una diferente circunscripción territorial.

Pero este Juez «más próximo geográficamente al presunto trastornado», en el momento en que dicho trastorno psíquico tenga lugar, no sólo será el competente para acceder al «internamiento", sino también para controlar la conveniencia de su mantenimiento duran-

37 Vid., el AAP de Lleida, de 3 de octubre de 2006, r. 44294, dónde se afirma que «la competencia inicialmente atribuida a un determinado Juzgado no variará ante el traslado del interno, debiendo ser el Juez que autorizó la medida del internamiento, quién asuma su fiscalización, al objeto de acordar, en su caso, las convenientes medidas de control, continuación o archivo». 
te todo el tiempo en el que dure o para acordar, en otro caso, su inmediato alzamiento.

La eventual práctica, muy habitual, por lo demás, de traslados a otros centros, - por razón de la conveniencia del traslado a un centro dónde se garantice una mejor atención y tratamiento del trastorno que, en concreto, aqueje al «interno» o por razones meramente funcionalesdurante el tiempo que dure el internamiento, complicará considerablemente la labor de "control» que deba efectuar el Juez de un lugar diferente a aquél en el que este internamiento se está produciendo.

Al igual que reivindicamos, en el epígrafe destinado a la competencia para el conocimiento de las pretensiones sobre la capacidad de las personas, también aquí, en materia de «internamiento involuntario por razón de trastorno psíquico», nos parece conveniente la creación de Juzgados específicos, en todas las provincias de España, para la resolución de este peculiar tipo de procedimientos y ello tanto por razones de "especialización», como de «economía procesal», e, incluso, de «sensibilización».

\section{B. Emplazamiento}

Aún cuando el Ministerio Fiscal no ostentará, con carácter general, la posición de "parte» en este tipo de procesos — salvo que alguno de los interesados sea menor, incapacitado o esté en situación de ausencia legal, ex. art. $749.2^{\circ}$ LEC-, lo cierto es que su presencia deviene, ello no obstante, preceptiva si tomamos en consideración que el Juez, antes de conceder la autorización o ratificar el internamiento, habrá de oír, necesariamente, - por así preverlo, con carácter imperativo, el precepto $763.3^{\circ}$.I de la LEC-, al Ministerio Fiscal.

De esta evidencia se infiere que el Juez habrá de dar traslado de la "solicitud de internamiento", además de a la persona, en concreto, afectada por esta gravosa medida, al Ministerio Fiscal.

La necesidad de advertir al interesado la razón de su «internamiento", que ha sido expresamente resaltada por miembros del Poder Judicial $^{38}$, encuentra su fundamento en el derecho de defensa, toda

38 Vid., LÓPEZ-BARJA DE QUIROGA, J., quién ha señalado, en este sentido, que "quién tiene derecho a interponer un recurso para una decisión rápida sobre la legalidad de su detención, no podría prevalecerse de él eficazmente si no se le revelan en el más corto plazo y en grado suficiente los hechos y las reglas jurídicas invocadas para privarle de su libertad», en «El internamiento de enajenados», Poder judicial n. ${ }^{\circ} 4,1986$, p. 57. 
vez que la persona, en concreto, afectada por la «autorización" o, en su caso, por la "ratificación» del internamiento, difícilmente podrá hacer frente a dicha medida, a través de la contestación a dicha pretensión o, en su caso, del oportuno recurso, si desconoce la causa esto, es, el concreto "trastorno psíquico»- que motivó la petición de su «internamiento».

\section{PRÁCTICA DE LA PRUEBA DE CARGO DESTINADA A FORMAR LA CONVICCIÓN JUDICIAL SOBRE LA "AUTORIZACIÓN»O «RATIFICACIÓN"DEL INTERNAMIENTO}

El precepto $763.3 .^{\circ}$ de la LEC dispone que «antes de conceder la autorización o de ratificar el internamiento que ya se ha efectuado, el Tribunal oirá a la persona afectada por la decisión, al Ministerio Fiscal y a cualquier otra persona cuya comparecencia estime conveniente o le sea solicitada por el afectado por la medida. Además, y sin perjuicio de que pueda practicar otra prueba que estime relevante para el caso, el Tribunal deberá examinar por sí mismo a la persona de cuyo internamiento se trate y oír el dictamen de un facultativo por él designado. En todas las actuaciones, la persona afectada por la medida de internamiento podrá disponer de representación y defensa en los términos señalados en el artículo 758 de la presente Ley».

\section{A. Audiencia a la persona afectada, al Ministerio Fiscal y a cualquier otra persona cuya comparecencia estime, el Juez, conveniente o le sea solicitada por el afectado por la medida}

La «audiencia», efectuada por el Juez, a la persona, en concreto, afectada por el internamiento es fundamental para preservar el principio de contradicción, no pudiendo, de ninguna manera, ser sustituida, tal y como se ha advertido ${ }^{39}$, por el informe médico.

La preceptiva práctica de esta audiencia, a la persona afectada por el «internamiento» y al Ministerio Fiscal, así como, en su caso, a las personas que el propio Juez o aquella persona estimen oportuno, ofrece una triple ventaja: así, en primer lugar, permitirá al Juez efec-

39 Vid., en este sentido, CUTILLÁS TORNS, J. M., "Consideraciones sobre el internamiento de presuntos incapaces», RJE La Ley, 1988-1, p. 876. 
tuar una «evaluación» directa del afectado por la medida, al objeto no sólo de "analizar" su presunto "trastorno psíquico" - para cuyo estudio ya existen dos pruebas preceptivas, como lo son el examen judicial y el informe médico- sino, sobre todo, de conocer su verdadera "voluntad» frente a esta medida; en segundo lugar, la audiencia del Ministerio Fiscal, que velará por la puridad del procedimiento, supondrá, sin ninguna duda, una garantía de inestimable relevancia práctica, tanto en el plano del procedimiento, como, en su caso, en el sustantivo, toda vez que este Ministerio Fiscal promoverá la acción de incapacitación cuando detecte, como consecuencia de la práctica de aquel internamiento, la existencia de una "enfermedad o deficiencia» que inhabilite a la persona para el autogobierno; $y$, finalmente, la audiencia de las personas próximas a quién se encontrase afectado, en un determinado momento, por una medida de protección consistente en su «internamiento» con fines terapéuticos, permitirá, a Juez, obtener una información muy valiosa sobre la persona presuntamente aquejada por un «trastorno psíquico».

\section{B. Examen de la persona afectada por la solicitud de «autorización» o «ratificación» del internamiento}

La virtualidad de este examen judicial directo e inmediato, de la persona, supuestamente afectada por un trastorno psíquico reside no sólo en la supervisión judicial de los síntomas de la persona, convenientemente detectados por los facultativos, sino, esencialmente, en la evitación de pretensiones de "internamiento" amparadas en motivaciones diferentes a las que deben presidir este tipo de procedimientos y que son, de un lado, la "protección de la persona" y, de otro, su rápido "restablecimiento".

El examen de la persona afectada por un trastorno psíquico, se efectuará, ante la solicitud de "autorización» del internamiento, con carácter general, en el momento de la vista oral, celebrada, como es lógico, en las dependencias del Juzgado.

El examen de la persona afectada por un trastorno psíquico que ya se encontrase internada por razones de urgencia no podrá efectuarse, sin embargo, en un buen número de casos, en el Juzgado —debido a las condiciones en que se encuentra el paciente- debiendo el Juez desplazarse al lugar en dónde se encontrase dicha persona para proceder, con la debida inmediación, a su examen.

La práctica judicial de este examen habrá de hallarse presidida por idénticas garantías y similares formalidades a las que hemos 
enunciado en el epígrafe destinado a esta misma cuestión en los procesos de incapacitación.

Y al igual que en los procesos de incapacitación, parece evidente que también en los de «internamiento involuntario por razón de trastorno psíquico" deba resultar este "examen" una conditio sine qua non de la emisión de resolución judicial. Pese a ello, algunos autores ${ }^{40}$ nos han alertado sobre el incumplimiento, en un porcentaje elevado, de esta medida.

La ausencia del «examen judicial», durante las 72 horas siguientes al momento en que, el Juez, tenga conocimiento de la práctica del internamiento debiera suponer, en línea de principio, la "puesta en libertad» de la persona presuntamente aquejada por un «trastorno psíquico», pero esta solución deviene, en la inmensa mayoría de los casos, muy inconveniente, de dónde se infiere que la práctica sanitaria del «mantenimiento» del interno, en las instalaciones hospitalarias, sin la oportuna «ratificación judicial», parece, pese a contradecir el mandato legal, el mal menor. Y es que la continuidad, en el tiempo, del «internamiento" de personas afectadas por «trastornos psíquicos graves", que se encuentran en casos extremos de delirio, no debiera depender del «atasco» de nuestros Juzgados y Tribunales.

\section{Dictamen de un facultativo designado judicialmente}

El fundamento de la «designación judicial» del facultativo que ha de elaborar el dictamen reside en la necesaria «imparcialidad», «neutralidad» $\mathrm{y}$ «objetividad» que ha de presidir la actividad de este profesional de la Medicina, parangonable, por lo demás, a la predicable de los Jueces y Tribunales, en esta función previa al enjuiciamiento, que, pese a hallarse encomendada a los especialistas en "trastornos psíquicos», resulta, en buena medida, constitutiva de un "prejuicio" sobre el resultado del juicio, que se ventilará, necesariamente, con un pronunciamiento judicial sobre la «conveniencia» $o$ «inoportunidad» del internamiento.

40 Vid., SÁEZ GONZÁLEZ, J., quién analiza las estadísticas de un estudio, en el que, entre otros resultados desoladores, parece ser que un $66 \%$ del total de «internos forzosos" fueron, en un concreto período de tiempo, dados de alta antes de que llegara la autorización judicial a la unidad. Y es que resulta evidente, tal y como señala este autor, tras ilustrarnos sobre este dato, que «strictu sensu hubiera debido procederse a la puesta en libertad de todos los enfermos cuya autorización judicial no hubiera llegado antes de 72 horas", en "Algunas consideraciones sobre regulación de los internamientos psiquiátricos», Justicia, I-II, 1998, p. 118. 
La LEC no concreta, en su alusión al «facultativo designado judicialmente», si por tal habrá de entenderse un concreto "especialista» en trastornos psíquicos o cabe acudir a un Médico general, ni tampoco si dicho "facultativo" ha de serlo de la Sanidad pública -así, los Forenses de los Juzgados, que son, por lo demás, conforme establece el precepto 381 de la LECrim., quiénes realizan, en el proceso penal, la "observación» del procesado cuando el Juez advierte indicios de enajenación mental - o, en su caso, podría acudirse a la Sanidad privada. Parece razonable que sean los Forenses quiénes acometiesen, con la debida neutralidad, la elaboración de este dictamen, salvo que por razón de la «especialidad» hubiere de acudirse, excepcionalmente, a otros concretos profesionales, probablemente, de la Psiquiatría.

La expresión utilizada por la LEC — «oír el dictamen de un facultativo"- para referirse al examen Médico del "presunto trastornado» no ha de ser interpretada en sentido estricto. Así, pues, por la expresión verbal «oír» cabrá entender tanto la efectiva audición del dictamen, emitido verbalmente, por el facultativo, en una vista oral o, en su caso, de manera informal -que se practicará, generalmente, en los supuestos de máxima urgencia, que vienen referidos, por lo común, a la «ratificación de la medida»-, como a la obtención, en un escrito, del informe médico, en el que se verifica la existencia o, en otro caso, la inexistencia del «trastorno psíquico».

La práctica habitual, según la información emitida al respecto por los miembros del Poder Judicial dedicados ${ }^{41}$, entre otras materias, a la adopción de este tipo de resoluciones sobre el internamiento, consiste en que el Médico forense examine, conjuntamente con el Juez, al enfermo, en unidad de acto.

Ahora bien, conviene precisar que, pese a la aparente analogía existente en la tramitación de ambos tipos de procedimientos, el dirigido a la obtención de la "autorización" requerirá la obligatoria realización de un solo dictamen Médico, frente a los dos o, incluso, tres dictámenes médicos emitidos, en la praxis de los destinados a la «ratificación del internamiento", toda vez que en este último tipo de procedimiento, tras una primera atención médica, se efectúa, generalmente, una segunda evaluación del «trastorno", en concreto apre-

${ }^{41}$ Vid., en este sentido, PATROCINIO POLO, J. A., quién, al propio tiempo, señala que esta práctica habitual de nuestros Juzgados y Tribunales es muy útil y conveniente, en «El internamiento de los presuntos incapaces. Aspectos procesales y sustantivos», www.futuex.com. 
ciado, por el facultativo especializado, ya en el centro de internamiento, y aún un tercer examen, por el forense en el juicio.

Aún cuando la exigencia del «dictamen de un facultativo designado judicialmente» resulta preceptiva, tanto en los procesos destinados a la «autorización judicial del internamiento», como en los celebrados para la obtención de la «ratificación» del internamiento ya practicado -n el que, obsta matizar, ya ha intervenido un "facultativo", concretamente el que atendió al enfermo en el centro dónde se practicó el internamiento-, lo cierto es que distintos especialistas en la materia se han hecho eco de la latente discriminación existente -así, la presencia de dos facultativos en los procesos de ratificación frente a la de un facultativo en los de autorización de internamiento--, en la práctica, entre unos y otros procesos y han reclamado la exigencia de la emisión de dos dictámenes médicos -uno, efectuado por el facultativo designado judicialmente y otro por el que ha venido atendiendo, habitualmente, al enfermo psíquico - en ambos tipos de procedimientos, y ello por razón de la necesidad de establecer un adecuado equilibrio entre la «responsabilidad» del diagnóstico y tratamiento efectuados en el dictamen sobre la conveniencia del internamiento, que será mejor estudiada y asumida por dos profesionales de la Medicina en lugar de por uno, además de por la correlativa coherencia interna que deba caracterizar la resolución judicial ${ }^{42}$.

\section{EFECTOS DE LA RESOLUCIÓN JUDICIAL Y RECURSOS}

Aún cuando la Ley no se pronuncia sobre la forma que deba adoptar esta resolución en la que se accede o desautoriza el «internamiento" solicitado y, en su caso, el ya efectuado, y lo habitual es que se haga a través de "auto», lo cierto es que parecería conveniente que dicha resolución adoptase la forma de sentencia, toda vez que, estando en juego un derecho fundamental de tal entidad como lo es el derecho a la libertad de las personas, debieran, a nuestro juicio, extremarse las cautelas, concretadas, en este ámbito de actuación, en

42 Vid., en este sentido, CASTELLANO ARROYO, M. C.; MINGORANCE CANO, C; y GASSÓ ARIAS, M., quiénes, al propio tiempo, aciertan rotundamente al expresar que «si el alta médica se deja a criterio de los facultativos que internan al enfermo, también el internamiento debe contar con la indicación de los facultativos del centro. Podría calificarse de hipócrita el que el Médico o el Centro estuvieran obligados al internamiento con base en la resolución judicial y que estuvieran autorizados a dar el alta a los pocos minutos de haberse producido el mismo», en «El internamiento psiquiátrico compulsivo y la incapacitación en la nueva Ley de Enjuiciamiento Civil», Actualidad Civil n' 26, 29 de junio, 2003, p. 677. 
las exigencias del derecho a la sentencia motivada, razonable, congruente, en cuánto ello fuera posible, con las pretensiones de las partes y, naturalmente, fundada en derecho. Y es que la resolución en la que el Juez se pronuncia sobre un «internamiento involuntario por razón de trastorno psíquico" se halla íntimamente conectada o, de cualquier modo, vinculada, aunque ambos tipos de pretensiones deban ventilarse en diferentes procedimientos, con la capacidad de las personas, que obviamente se verá limitada cuando «ingresan», sin o contra su voluntad, con fines terapéuticos, en un centro cerrado. Ante esta evidencia no se comprende bien por qué las resoluciones dimanantes de los procesos dedicados, en general, a la constitución, reintegración o modificación de la «incapacitación» o, en su caso, de la "prodigalidad", han de revestir necesariamente la forma de "sentencia» y basta, sin embargo, para las destinadas al «internamiento civil forzoso", la adopción de la forma de «auto».

\section{RESOLUCIÓN JUDICIAL DE LA «AUTORIZACIÓN»O "RATIFICACIÓN" DEL INTERNAMIENTO Y SU CONTROL}

La resolución que autoriza o ratifica el internamiento es constitutiva de una nueva situación jurídica, la del internamiento, con efectos ex nunc, esto es, desde el momento en que dicha sentencia ha sido dictada.

La sentencia que deniega el internamiento será declarativa cuando el objeto del proceso hubiere venido integrado por una pretensión de "autorización" del internamiento y, sin embargo, será constitutiva cuando aquel objeto hubiere venido integrado por la petición de «ratificación" del internamiento, dado que en el primer caso se limita a declarar la validez de la situación preexiste, mientras que en el segundo, la sentencia crea, modifica o constituye una nueva situación jurídica.

$Y$ es que frente a las resoluciones que «autorizan» o «ratifican», pero desde luego, no «imponen», ni mucho menos «obligan», a la realización del internamiento, se alza aquella otra destinada a "desautorizar», «denegar» o «desaprobar» la «ratificación» del internamiento ya efectuado, constituyendo esta última resolución, sin embargo, tal y como ya se ha tenido ocasión de subrayar ${ }^{43}$, una «or-

${ }^{43}$ Vid., en este sentido, FÁBREGA RUIZ, C. F., "Las autorizaciones de internamiento. Problemática de su aplicación a los discapaces psíquicos», en «Discapacidad intelectual y Derecho», IV Jornadas Fundación Aequitas, Madrid, 2004, p. 246. 
den judicial» destinada a «dar el alta», en el marco del proceso civil, al paciente, en contra del criterio médico.

En la misma resolución que acuerda el internamiento, según dispone el precepto $763.4{ }^{\circ}$ de la LEC, se expresará la obligación de los facultativos que atienden a la persona internada de informar periódicamente al Tribunal sobre la necesidad de mantener la medida, sin perjuicio de los demás informes que el Tribunal pueda requerir cuando lo crea pertinente. Los informes periódicos serán emitidos, según prosigue este mismo precepto, cada seis meses, a no ser que el Tribunal, atendida la naturaleza del trastorno que motivó el internamiento, señale un plazo inferior. Recibidos los referidos informes, el Tribunal, previa la práctica, en su caso, de las actuaciones que estime imprescindibles, acordará lo procedente sobre la continuación o no del internamiento. Sin perjuicio de lo dispuesto en los párrafos anteriores, cuando los facultativos que atiendan a la persona internada consideren que no es necesario mantener el internamiento, darán el alta al enfermo, y lo comunicarán inmediatamente al Tribunal competente.

La resolución judicial de la «autorización» o «ratificación» del internamiento habrá de venir referida, respecto de una determinada persona, a su concreto «internamiento», por el específico «trastorno psíquico» que le aqueja, en ese preciso momento, sin que pueda resultar extensible, como es lógico, a la posibilidad o facultad de realizar sucesivos «internamientos» cuando, una vez dada el alta del paciente, reaparezcan, debido a la naturaleza cíclica del «trastorno», los síntomas que motivaron su anterior «internamiento». En tales casos, habrán de realizarse tantos procesos de esta naturaleza, frente al «presunto trastornado», como «internamientos» sean convenientes.

La resolución judicial en la que se «autoriza» o «ratifica» el internamiento habrá de pronunciarse, en exclusiva, sobre esta concreta limitación del derecho a la libertad de las personas, sin que pueda, al propio tiempo, extenderse a otros derechos, como lo serían, en su caso, los derechos a "recibir visitas», realizar llamadas telefónicas, utilizar todos los servicios existentes a disposición de los pacientes, etc., - salvo que el estudio médico aconseje, durante concretos períodos de tiempo, ante la gravedad del trastorno, la adopción de ciertas soluciones de «aislamiento» - con excepción de que aquellas pretensiones hubieren sido oportunamente propuestas en el mismo proceso y el Juez hubiere accedido a su conocimiento y aceptación.

En la resolución judicial que acuerde o ratifique el internamiento, el Juez podrá, asimismo, pronunciarse sobre la paralela «autoriza- 
ción» del tratamiento médico no voluntario por razón de trastorno psíquico, siempre, claro está, que dicha "autorización» hubiere sido oportunamente solicitada por el actor ${ }^{44}$, toda vez que esta última "pretensión", de efectuarse al margen del proceso del internamiento, se canalizaría, por los trámites de la jurisdicción voluntaria y no cabe duda - si tomamos en consideración la idéntica posibilidad, legalmente reconocida, de acumular, en el proceso de incapacitación, a la propia pretensión de incapacitación, la del nombramiento del tutor o curador, que, de solicitarse aisladamente, habria de reconducirse a la jurisdicción voluntaria - al respecto de la posibilidad e, incluso, de la conveniencia de la acumulación de ambas pretensiones.

Pero no sólo el sometimiento forzoso, del interno, a un determinado tratamiento ${ }^{45}$ - sin que concurra, por tanto, el «consentimiento informado» ${ }^{46}$ - habrá de ser objeto de pronunciamiento judicial específico, sino también, tal y como ya se ha advertido ${ }^{47}$, todas las es-

${ }^{44}$ BUSTOS VALDIVIA, I., opina, sin embargo, que «cuando se da la autorización judicial para internar, ya va implícito el consentimiento para el tratamiento, pues precisamente se interna porque, por la causa que sea, no se puede suministrar de forma ambulatoria", en "Consideraciones sobre el internamiento por razón de trastorno psíquico a partir de la Ley Orgánica de Protección Jurídica del Menor de 15 de mayo de 1996», Actualidad civil n ${ }^{\circ}$ 35, 25 de septiembre a 1 de octubre, 2000, p. 1297; En sentido contrario se pronuncia AZNAR LOPEZ, M., quién advierte que la autorización del Juez, en este tipo de procesos, «no habrá de dirigirse a autorizar el tratamiento, sino única y exclusivamente a la privación de un derecho fundamental, como es la libertad", en "Internamientos civiles y derechos fundamentales de los usuarios de centros sanitarios, sociales y sociosanitarios", Ed. Comares, Granada, 2000, p. 63.

45 El sometimiento forzoso, del enfermo, a un tratamiento Médico adecuado a la dolencia que padezca, constituye, por lo demás, en el marco de los «internamientos penales» una obligación de las instituciones penitenciarias que, tal y como afirma, ARRIBAS LOPEZ, J. E., tienen el deber de velar por la vida, integridad y salud de los internos, en «Breves consideraciones sobre la asistencia médica forzosa a los internos en los centros penitenciarios", Actualidad Jurídica Aranzadi n ${ }^{\circ} 705$, mayo, 2006, p. 2.

${ }^{46} \mathrm{Si}$ el enfermo, en concreto, afectado por la medida de protección - recomendada por el Médico, en el ejercicio de sus funciones facultativas - no está en condiciones, a juicio del Fiscal, de dar su consentimiento o la adopción de aquella medida, en otro caso, pudiera transgredir el ordenamiento jurídico, entonces, este Fiscal deberá, tal y como se advierte en el Auto de la AP de Sevilla, de 11 de diciembre de 2003, r. 100275 , promover el oportuno proceso declarativo de incapacidad, en el que se valore su capacidad para valorar y dirigir su persona y bienes, con adopción de medidas de protección adecuadas o, en su caso, ejercitar las acciones de otra índole que considere oportunas.

47 Vid., SANTOS MORÓN, M. J., cuando advierte que «si el Juez se limita a autorizar el internamiento sin especificar el alcance de la privación de libertad, creemos que debe entenderse que la autorización abarca sólo las limitaciones derivadas de la prohibición de salir del edificio de que se trate. Limitaciones ulteriores, como la reclusión en una sala de aislamiento o el empleo de dispositivos mecánicos o químicos que mantengan inmovilizado al interno deben contar, en nuestra opinión, con una de- 
pecíficas prescripciones médicas que supongan, al propio tiempo, una limitación a la libertad de aquél interno. Esto no significa, como es lógico, que los facultativos y trabajadores, en general, de los centros de internamiento dónde se reestablecen los enfermos psíquicos deban acudir a los Tribunales en cada ocasión en la que su actuación, siempre en beneficio del paciente, se extralimite lo más mínimo, - como sería el caso, a modo de ejemplo, de la utilización de métodos de «resistencia» o «reducción» de personas agresivas o violentas cuando ello fuere necesario por razón del «tratamiento»- pero sí que la resolución judicial sea suficientemente comprensiva, siquiera sea con tintes de generalidad, del margen de discrecionalidad otorgado a los sanitarios y cuidadores, en general, de estos «internos» para evitar, llegado el caso, la comisión de abusos y atentados a la dignidad, así como de tratos humillantes, inhumanos o degradantes.

La adopción judicial de la resolución que acuerde el internamiento, así como las sucesivas resoluciones que admiten, en su caso, la continuación de dicho internamiento habrán de ser, como es lógico, suficientemente motivadas. Y no sólo porque se trata de una decisión que incide directamente en algunos derechos fundamentales de la persona, sino porque su adopción no podrá sustentarse en el mero aislamiento de la persona afectada, sino que habrá de encontrar un claro fundamento en su debida protección.

En este sentido, desde sectores de la Judicatura ${ }^{48}$, próximos al tema tratado, nos han llegado algunas noticias escalofriantes sobre la inconveniencia, en ciertos supuestos, del internamiento, debido a las penosas condiciones existentes en algunos centros, lo que, paralelamente, nos ha alertado sobre la imperiosa pertinencia de una constante "vigilancia» y "control» judiciales de dichos internamientos.

cisión judicial que lo autorice expresamente. Sólo de este modo se garantiza adecuadamente el respeto a la dignidad y demás derechos fundamentales del paciente internado", en "El supuesto de hecho del internamiento en el artículo 763 LEC 1/2000», Ed. Tirant lo blanch, Valencia, 2002, pp. 72 y 73.

${ }^{48} \mathrm{Vid}$., al respecto, ORTIZ GONZÁLEZ, A. L., quién nos informa sobre algunos métodos, utilizados en ciertos hospitales psiquiátricos -así, entre otros, el aislamiento absoluto en cuartos cerrados mediante puertas metálicas con grandes cerrojos, piernas atadas a la cama en habitaciones cerradas o, en fin, sujeción a las camas por las muñecas-, que no parecen, desde luego, acordes con el «tratamiento» que debiera ser dispensado a los internos al objeto de su recuperación, y respecto de cuya utilización nunca tuvieron conocimiento los jueces competentes, debido a que en todos aquellos casos no se les había comunicado la adopción de las medidas descritas, en "La protección de los incapaces. Actuaciones del defensor del pueblo", en "Los discapacitados y su protección jurídica», Estudios de Derecho Judicial, n. ${ }^{\circ} 22$, Consejo General del Poder Judicial-Consejo General del Notariado, Madrid, 1999, p. 257. 
Aún cuando el «internamiento" y la "incapacitación» son, como se ha visto, dos procesos especiales independientes y autónomos, lo cierto es que de las continuadas "prórrogas del internamiento" puede inferirse, según ha señalado la doctrina ${ }^{49}$, la necesidad de una "incapacitación». Resulta, en síntesis, evidente que tan "perjudicial» puede resultar la «incapacitación» para un interno, afectado, en un determinado momento, por un "trastorno psíquico» ocasional o pasajero, como "beneficiosa" para quién deba permanecer en un centro psiquiátrico durante un prolongado período de su vida o, incluso, durante toda su vida.

Aún cuando el control sobre la conveniencia del mantenimiento de la medida consistente "internamiento» o, en otro caso, sobre su alzamiento corresponde, teóricamente, al Juez ${ }^{50}$, lo cierto es que, en la práctica, son los facultativos que atiendan a la persona internada, quiénes darán el alta al enfermo cuando consideren que no es necesario mantener el internamiento, comunicándolo, eso sí, inmediatamente al Tribunal competente.

La redacción inicial del precepto, según se nos recuerda ${ }^{51}$, dejaba al arbitrio exclusivamente judicial, nada menos que el «alta del paciente». Esta excesiva "judicialización» del «internamiento» fue, afortunadamente desechada. No debe olvidarse que el Juez, en este proceso civil especial, «autoriza» el «internamiento», no lo «ordena».

49 Vid., en este sentido, BERCOVITZ RODRÍGUEZ-CANO, R., cuando afirma que "en los internamientos involuntarios prolongados una incapacitación parece necesaria, aunque se limite a los aspectos personales y no afecte a la esfera patrimonial del incapacitado», en "Comentario al artículo 211", "Comentarios a las reformas de nacionalidad y tutela», Ed. Tecnos, Madrid, 1986, p. 206.

50 En este sentido, la AP de Castellón ha advertido, en su sentencia de 9 de octubre de 2004, r. 313351, que el seguimiento y control del internamiento, que constituye la ejecución de la autorización decretada judicialmente, corresponderá al Juez que autorizó o ratificó esta medida, sin que un eventual cambio del concreto "centro de internamiento" en el que se encontraba inicialmente el enfermo, modifique la competencia.

${ }^{51}$ MAGRO SERVET, V., quién reproduce el texto de la redacción inicial del Proyecto de Ley (BOCG de 13 de noviembre de 1998) - «sin perjuicio de lo dispuesto en los párrafos anteriores, cuando los facultativos que atienden a la persona internada consideren que no es necesario mantener el internamiento lo comunicarán inmediatamente al Tribunal, para que resuelva lo procedentes-con advertencia de que la enmienda que suprime el punto final encuentra su justificación en que «suprimir la necesidad de que el Juez se pronuncie sobre la decisión de los facultativos con respecto a la determinación del alta de la persona internada cuando así lo estime procedente», en "La modificación legislativa de las medidas de internamiento no voluntario de personas por razones psíquicas en la nueva Ley de Enjuiciamiento Civil», RJE La Ley n. ${ }^{\circ}$ 5060, 2000, p. 1459. 
El proceso de internamiento involuntario por trastorno psíquico finaliza cuando se produce el «alta» del paciente. Se presupone, cuando se produce el "alta», que el paciente se ha reestablecido, si no de modo completo, sí al menos considerablemente.

El «alta» médica de la persona afectada por el internamiento no supone, de modo necesario, el completo reestablecimiento de su capacidad, pudiendo, en su caso, permanecer «incapacitada» - si persiste la «enfermedad o deficiencia persistente que la inhabilita para el autogobierno»-, una vez haya sido puesta en «libertad", pero sí supondrá la desaparición o, al menos, la mengua o minoración de la causa que, en concreto, motivó el internamiento, que lo fue, como es sabido, el «trastorno psíquico».

La finalización del proceso constituye, en este sentido, otra de las notas que diferencian ambos tipos de procesos. En este sentido, el proceso de "incapacitación" finalizará con una sentencia que, de ser estimatoria de la pretensión deducida por la parte demandante, constituirá una nueva situación jurídica, la de la «incapacitación», que tan sólo será reversible ante la celebración de un segundo proceso, el de la reintegración de la capacidad o modificación, en su caso, del alcance de la incapacitación.

El proceso de «internamiento involuntario por razón del trastorno psíquico» finalizará, sin embargo, con el «alta» del facultativo, sin que resulte preceptiva, al propio tiempo, la práctica de una supervisión judicial, ni mucho menos la celebración de otro procedimiento.

El «alta» corresponde a los facultativos, que habrán de limitarse, de manera conjunta a la elaboración de este «alta», a comunicarla al Tribunal competente. Esta facultad, atribuida a los facultativos, de poner término al proceso en el momento en que consideren conveniente, sin mayor «control» $\mathrm{u}$ «homologación judicial» que una mera comunicación, se justifica ante la evidencia de que la autorización y, en su caso, la ratificación judicial del «internamiento involuntario por razón de trastorno psíquico» constituyen meras "autorizaciones», nunca obligaciones strictu sensu.

Los facultativos asumen, pues, en el momento final del «internamiento», en atención al otorgamiento de esta excepcional facultad, una función generalmente reservada a los Jueces, la de la decisión, sin mayor vigilancia ni control, sobre el término de este procedimiento como consecuencia bien de la completa desaparición del "trastorno psíquico» que, en concreto, motivó ese internamiento, o bien de la conveniencia de la devolución, a la persona afectada por 
aquella medida de protección, de la libertad ambulatoria, como consecuencia de una notable aminoración de las causas que provocaron, en su día, dicho trastorno.

La razón de ser de la discrecionalidad, predicable la «decisión» de los facultativos, sobre la "continuación» o "finalización» de este tipo de procesos, reside, asimismo, como es lógico, en su mayor y mejor "conocimiento» del «interno», y ello desde múltiples perspectivas, desde las estrictamente psiquiátricas —n las que serán especialistas - hasta las cotidianas - los internos psiquiátricos reciben un seguimiento médico diario-, pasando por las de mera "conveniencia", "rapidez» y "eficacia».

Es por todos sabido que las personas sometidas a «internamientos» de media o larga duración encuentras grandes dificultades de adaptación al mundo exterior cuando deben, al fin, salir de los centros en los que estuvieron recluidos para reiniciar una vida en libertad. Ello explica que los "facultativos» no hagan coincidir, exactamente, el "momento" en que ha desaparecido el "trastorno psíquico» con el del «alta», en la medida en que resulta conveniente la «prolongación» de esta estancia por un período en el que deba prepararse a la "persona", desde su completo restablecimiento psicológico, para afrontar una nueva vida en sociedad ${ }^{52}$.

La concreción del momento el que la persona deba ser dada de alta constituye, en todo caso, una decisión de vital importancia, toda vez que el mantenimiento de la medida de protección en que consiste el "internamiento» de quién, pese a ello, se encuentra en condiciones óptimas para afrontar la «vida en libertad» podría ocasionarle, sin lugar a dudas, un perjuicio de difícil reparación.

Cabe, en este momento, preguntarse si el proceso puede finalizar por la simple decisión de las personas que, en su momento, lo promovieron. Y la respuesta podría ser, dado que nada se dice al respecto, la destinada a los restantes procesos sobre la capacidad de las personas. No cabría la renuncia por la evidente «indisponibilidad» del derecho tutelado en de este concreto proceso y el desistimiento requeriría, en su caso, la conformidad del Ministerio Fiscal.

52 Sobre estas naturales dificultades, vid., ARIZA SEGOVIA, S., quién reconoce «la poca preparación para esa vida exterior y los efectos de la dependencia, lo que hace desaconsejable una ruptura brusca con la institución», en "Significado y efectos del internamiento en instituciones de acogida infantiles y juveniles», Ed. Universidad Complutense, Madrid, 1993, p. 510. 
Aún cuando los efectos derivados de la «renuncia» y el «desistimiento", en la generalidad de procesos civiles, carecen de la menor analogía - habida cuenta de la "cosa juzgada" predicable de las resoluciones en las que se constata la renuncia al concreto derecho hecho valer en el proceso, por contraposición a la ausencia de cosa juzgada evidenciable en las resoluciones que ponen término al proceso como consecuencia del desistimiento- lo cierto es que los efectos dimanantes de los actos de disposición del objeto del proceso a los que acabamos de referirnos, en este peculiar proceso, son muy similares. Así, pues, el desistimiento del proceso supondrá -al igual que acontecería, por cierto, con la renuncia, si ésta resultase admisible - la finalización de éste en un determinado momento con reserva de la propia acción para un momento ulterior. Y este proceso finaliza, no lo olvidemos, cuando se produce el «alta» del paciente.

Así, pues, la finalización anticipada del proceso como consecuencia del desistimiento, manifestado por la parte actora y consentido por el Ministerio Fiscal, supondría nada menos que el alzamiento del «internamiento» en un momento anterior al que habría sido considerado, en otro caso, como «oportuno", por el único especialista en la materia, el Médico. Y ello naturalmente sin perjuicio de la posibilidad de instar un nuevo "proceso de internamiento involuntario" en el futuro, frente a la misma persona, por una nueva «manifestación» o, en su caso, un nuevo «brote» de su supuesto «trastorno psíquico». No nos parece razonable, de cualquier modo, que deba primar el «criterio familiar» frente al «médico» en este tipo de procesos de «internamiento involuntario" en los que está comprometido el interés general en la protección de las personas aquejadas por una evidenciable ausencia de salud mental.

Si a lo largo del tiempo de duración del «internamiento» se produjese una notable amortiguación o, incluso, la completa desaparición del concreto y específico «trastorno psíquico» que lo motivó, pero apareciese, ello no obstante, otro tipo de "trastorno", también psíquico, que, de cualquier modo, precisase la «continuidad del internamiento", entonces parecería razonable la exigencia de un segundo proceso en el que el Juez «ratificase» el mantenimiento del mismo internamiento, aún cuando por un trastorno de índole distinta al inicialmente prescrito.

Ahora bien, si las circunstancias concurrentes al momento de finalización de este proceso cambiasen en un momento ulterior $-y$ la persona afectada por el «internamiento" anterior volviese a requerir, por razón del surgimiento de un nuevo trastorno psíquico o reaparición del 
anterior, un nuevo internamiento - entonces, lógicamente, el procedimiento debería volver a comenzar. Esta posibilidad ha impulsado, a algún autor ${ }^{53}$, a considerar que este tipo de resoluciones carecen de los efectos de la cosa juzgada material. Nosotros nos inclinamos, más bien, por opinar que en ellas sí opera la cosa juzgada material, si bien con un infranqueable límite "circunstancial» o "temporal», esto es, sin perjuicio de que si cambian las circunstancias -al igual que acontece, por lo demás, con las restantes resoluciones dimanantes de los procesos sobre la capacidad de las personas- podrá incoarse un nuevo procedimiento entre las mismas partes en relación con los «nuevos hechos acontecidos». No debe olvidarse, por lo demás, la "provisionalidad», «transitoriedad» o «temporalidad» predicable, con carácter general, de las resoluciones sobre la capacidad de las personas y, muy especialmente, por razones obvias, dentro de aquellas, de las referidas, en particular, a los internamientos involuntarios por razón de trastorno psíquico.

En este sentido, las resoluciones judiciales destinadas a la «autorización" o "ratificación» del internamiento no gozan de efectos ilimitados en el tiempo. De ahí que si, ante la resolución favorable a "autorizar el internamiento», no se procediese a efectuar este "internamiento" con inmediatez, sino en un momento posterior, en el tiempo, a aquel en que se obtuvo la resolución judicial, resultaría conveniente promover un nuevo procedimiento, toda vez que las «circunstancias» concurrentes en aquél momento pudieron haber cambiado, y versando, el objeto de este tipo de procesos, sobre la privación de un derecho fundamental, como lo es la libertad, no debiera exponerse, a los afectados por algún "trastorno psíquico" del pasado, a soportar, en tales casos, «internamientos futuros». El internamiento involuntario por razón del trastorno psíquico constituye, fundamentalmente, una medida de «protección de las personas», no un «castigo».

La imperativa realización de «controles» de los internamientos ya producidos responde, asimismo, a la conveniencia de modificar el contenido de la resolución cuando desaparezcan, o al menos, cambien las "circunstancias" - lo que acontecería, a modo de ejemplo, cuando remitiese el "trastorno psíquico" lo suficiente como para que, el afectado por el internamiento, pudiese llevar, pese a no encontrarse absolutamente rehabilitado, una "vida normal»- que motivaron aquellos internamientos.

53 Vid., en este sentido, LACABA SÁNCHEZ, F., "Internamiento de incapaces: problemática del artículo 211 del Código Civil», RJE La Ley, 1993-4, p. 1017. 
La resolución judicial que autoriza o ratifica, así como la que, en su caso, desautoriza o desaprueba el «internamiento" goza, a nuestro juicio, -al igual que predicamos, en su momento de las sentencias sobre la capacidad de las personas - de los efectos materiales de la cosa juzgada, con una especial limitación temporal en atención a la eventual "variación" o "modificación» de los acontecimientos que dieron lugar, en su momento, a aquella resolución judicial. En este sentido, nos parece evidente que dicha excepción de cosa juzgada —al igual, en caso de pendencia del proceso, que la de litispendencia- debe prosperar cuando entre las mismas partes y por el mismo «internamiento", no habiéndose modificado en absoluto la situación de la persona, presuntamente afectada por un "trastorno psíquico», ya existe una resolución judicial anterior.

\section{RECURSOS}

El precepto $763.3 .^{\circ}$ III establece que «la decisión que el Tribunal adopte en relación con el internamiento será susceptible de recurso de apelación».

Frente a las resoluciones en las que se acuerde la «autorización» o la «ratificación" del internamiento, así como frente a las resoluciones en las que se denieguen ambas pretensiones, cabrá, pues, recurso de apelación, debiendo practicarse, de nuevo, en la segunda instancia, todas las pruebas legalmente exigidas para la primera.

La apelación interpuesta frente a la resolución que acuerde la «autorización» o la «ratificación» del internamiento no suspenderá, como es lógico, el internamiento al que se procederá de inmediato, ni mucho menos el ya efectuado.

La decisión que pone término a este proceso, tal y como se ha anticipado, es el «alta» del paciente, efectuada por el facultativo. Esta decisión no será susceptible, por razón de su procedencia no judicial, de recurso alguno, debiendo los particulares interesados en el mantenimiento del internamiento, limitarse a formular, ante el Juez competente, una solicitud de «autorización" para la práctica de un nuevo internamiento, en la que expongan, ante la nueva circunstancia descrita, y pese a la presunta persistencia del hipotético trastorno psíquico, la conveniencia de la adopción esta medida de protección.

Aún cuando nada dispone la LEC al respecto, frente a las sentencias dictadas en la segunda instancia de los procesos sobre el «inter- 
namiento involuntario por razón de trastorno psíquico de las personas», cabe, como es lógico, interponer el recurso de casación ante el Tribunal Supremo, toda vez que este tipo de procesos versan, principalmente, sobre el derecho fundamental a la libertad de las personas. 